Universidad de Lima

Facultad de Comunicación

Carrera de Comunicación

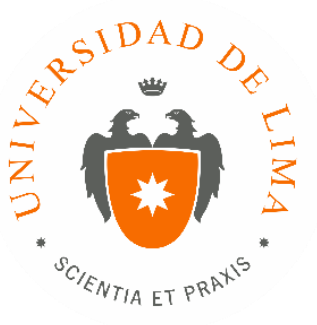

\title{
DE UNA FAMILIA RESPETADA A UNA FAMILIA AMADA: TÁCTICAS DE STORYTELLING EN EL CASO LOS APELLIDOS - SAN FERNANDO
}

Trabajo de Investigación para optar la licenciatura en Comunicación

\section{Andrea Fabiana Palacio Bonnett \\ Código 20100809}

\author{
Asesor \\ Julio Hevia Garrido-Lecca
}

Lima - Perú

Octubre de 2016 


\section{ÍNDICE}

RESUMEN pág. 1

PALABRAS CLAVE.................................................................. pág.2

INTRODUCCIÓN.................................................................pág.2

METODOLOGÍA...................................................................pág.6

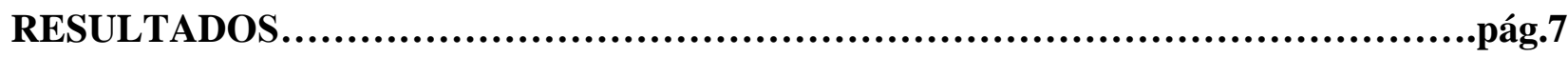

1.1 Resultados obtenidos de la entrevista a profundidad...........................pág.7

1.2 Resultados obtenidos de los focus group......................................pág.8

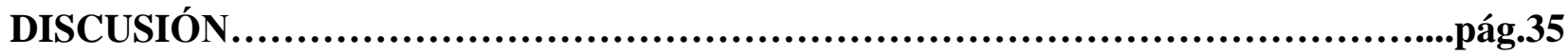

2.1 Rol y percepción en la compra.............................................pág.36

2.2 Recordación de campaña..................................................pág.36

2.3 Percepción de tácticas de storytelling.........................................pág.37

2.4 Percepción de marca previa a la campaña.....................................pág.38

2.5 Fidelización de la marca, a partir de las tácticas de storytelling...............pág.38

2.6 Conclusión..................................................................pág.39

REFERENCIAS........................................................................pág.40 


\title{
DE UNA FAMILIA RESPETADA A UNA FAMILIA AMADA: TÁCTICAS DE STORYTELLING EN EL CASO LOS APELLIDOS- SAN FERNANDO.
}

\author{
"Una marca debe ofrecer al consumidor una historia \\ en la que pueda actuar como personaje y en la que, al \\ hacerlo pueda ver realizados sus deseos y \\ aspiraciones...y se sienta gratificado"
}

- Xavier Ruiz Collantes

\section{RESUMEN}

Este trabajo busca analizar las tácticas del storytelling que utilizó la marca San Fernando en su relanzamiento con la campaña de "Los Apellidos" en el año 2011, y la percepción del público objetivo a partir de las mencionadas tácticas. Cabe mencionar la diferencia entre el carácter genérico de la estratégica y las tácticas como maniobras puntuales de la campaña, las cuales se desprenden de dicha estrategia. La marca San Fernando se personificaba como un ingeniero de unos 65 años, exigente y que nunca le daba un abrazo a sus hijos (Klingenberger, 2013). Este fenómeno se dio luego de su relanzamiento, ya que San Fernando pasó de ser una marca respetada que garantizaba calidad, a ser también amada y a volverse parte de la vida de los consumidores. Es decir, San Fernando dejó de representar distancia y frialdad, para representar cercanía y calidez.

Hoy en día estamos saturados de información y sobreexpuestos a anuncios publicitarios. Tan es así que tendemos a ignorar la gran mayoría de ellos, por lo que las marcas en Perú están empezando a utilizar cada vez más el tan antiguo storytelling o arte de contar historias. Este concepto es ahora conocido como una nueva forma del marketing de contenidos, mediante la cual podemos utilizar dichas historias para generar emociones en los 
consumidores y darle relevancia al contenido que la marca busca transmitir. En la presente investigación se utilizará como primera herramienta una entrevista a profundidad a un especialista del área de marketing de San Fernando para conocer cuáles fueron concretamente las tácticas de storytelling empleadas, y como herramienta principal cuatro focus group, para así poder comparar percepciones entre los distintos tipos de consumidores del target como las amas de casa y jóvenes.

PALABRAS CLAVE: Storytelling, estrategias publicitarias, narración transmedia, experiencia de marca, percepción de marca.

\section{INTRODUCCIÓN}

Sabemos que el storytelling o arte de contar historias no es nada nuevo, pero sí los usos que se le está dando a favor de la publicidad. Desde hace unos años, San Fernando y otras grandes empresas han entendido que el consumidor no está dispuesto a escuchar monólogos de parte de las marcas, sino que busca ser parte de ellas y de sus historias.

Estamos atiborrados de mensajes publicitarios y como consumidores hemos desarrollado diversos mecanismos de defensa para evitarlos, pero cuando el storytelling está 
presente resulta que la publicidad deja de ser solo eso, para convertirse en un medio de entretenimiento, una forma para contar una historia.

La campaña de "Los Apellidos”, nació de una necesidad de la marca San Fernando como empresa, ya que durante 60 años venía construyendo marca, pero enfocándose básicamente en la calidad de sus productos, ya que no tenía mucha presencia en los medios. En las investigaciones realizadas por la marca en el 2011, se observó que las amas de casa confiaban en la garantía que brindaba la marca San Fernando, pero no la querían, solamente la respetaban.

Luego de 60 años en los que la marca San Fernando había sido un negocio familiar, se decidió buscar a los profesionales más destacados del medio para que la puedan hacer crecer aún más, superando los límites de los productos. En ese momento se determinó que era necesario conectar emocionalmente con el consumidor, pero no de cualquier manera, sino relacionando aquello que era propio de San Fernando: la buena familia.

Parte de un buen storytelling es saber dónde contar la historia, y es aquí donde entra a tallar el concepto clave de la transmedialidad. La narración transmedia es un tipo de relato donde la historia se despliega a través de múltiples medios y plataformas de comunicación. Requiere crear contenido relevante, que vaya de acuerdo con lo que la marca quiere transmitir, y que además 'enganche' al público utilizando diferentes técnicas para impregnar su vida diaria. (Wikipedia, 2013)

Un buen ejemplo de storytelling es el de Lego. Esta fábrica de juguetes cuenta la historia de que la imaginación es el límite y los niños los protagonistas. El antagonista de Lego son los juguetes tradicionales que dan todo hecho, y el mensaje transmite la idea de que un niño es capaz de crear lo que desee y experimentar cuantas veces quiera con los bloques Lego.

Para efectos de esta investigación, además de la narración transmedia, también es importante tener en cuenta la relación del storytelling con la percepción de marca, que es el conjunto de representaciones mentales cognitivas y afectivas de un consumidor hacia la marca, que contribuyen para que se forme un concepto o postura hacia ella. 
Por otro lado, en investigaciones previas relacionadas al storytelling, hemos hallado que Henry Jenkins (2008) en su libro "Convergence Culture" sostiene que debido a la ya mencionada sobreexposición de mensajes, el marketing ahora trata de forjar reputación de marca. Pero no mediante una transacción individual, sino a través de una suma de interacciones con el consumidor, ya que los nuevos modelos de marketing pretenden incrementar relaciones emocionales con la marca.

Asimismo, Robert Pattern (2011) alude a un argumento similar acerca del storytelling en su libro "Getting Started in Transmedia storytelling”. Sostiene que nuestras mentes no son cautivadas por hechos u objetos aislados sin ninguna relación. Es por esta falta de interés que nosotros creamos nuestras propias historias para ir dándoles sentido. Inconscientemente vamos conectando puntos aislados, y aquellos que han sido unificados de una manera estimulante son los que llamamos buenas historias.

De igual modo se destaca en varias investigaciones el papel cotidiano del storytelling. Por ejemplo, en el libro "Las Siete Reglas del Storytelling” los autores sostienen que un hombre es siempre narrador de historias, pues vive rodeado de sus relatos y los de otros (Sadowsky y Loick, 2013). Tendemos a recordar más un mensaje cuando está ligado a una historia o a una anécdota, lo cual es muy importante en un mundo como el nuestro.

Ruiz Collantes (2010) también se refiere a la relevancia del storytelling en su artículo "Marcas para vender, historias para vivir. Marca, narración y sentido". Indica que ha habido una evolución de las marcas, en la cual ellas han pasado de ser una forma de categorizar y agrupar productos, a ser un ente cada vez más autónomo de ellos. Hace referencia además que las marcas ahora buscan fundamentalmente la diferenciación a través de los valores. San Fernando a partir de su relanzamiento ya no se centra en vender pollos, sino en comunicar la unión familiar, donde los productos son solo una excusa para reunirse y expresar que todos somos parte de La Buena Familia.

Por otro lado, con relación a investigaciones experimentales centradas en el storytelling, Lundqvist, Liljander, Gummerus y Van Riel (2013), realizaron una indagación que nombraron "The impact of storytelling on the consumer brand experience: The case of a firm-originated story" en la que separaron a dos grupos, mostrándole a uno un producto sin 
storytelling y al otro un producto que contaba con esta estrategia. El grupo al que se le expuso el producto vinculado a una historia describió la marca de una manera más positiva e incluso dijo que estaba dispuesto a pagar más por este.

Pierre Mora y Florine Liv (2013) concluyeron una premisa similar en su investigación nombrada "Does storytelling add value to fine Bordeux wines? En ella se descubre que el storytelling es percibido como un medio efectivo para entender mejor el posicionamiento de la marca de vinos Bordeaux; así como que la elevación del precio no se da por características del objeto en sí, sino por su posición simbólica y la imagen de lujo que evoca el producto, a partir de la historia narrada. Asimismo, cabe señalar que el storytelling no es solo parte de campañas publicitarias, también es beneficioso como medio de inspiración en las empresas, recurso para narrar un documental o para campañas políticas.

No faltan los especialistas como Eugenie Richard (2011), quien sostiene en su artículo "Storytelling, narrativas de campañas. Campañas electorales para la presidencia en Colombia 2010" que aquellos que han intentado conquistar la presidencia desde inicios de la República, han tenido que contar historias convincentes sobre la nación, sus problemas y sobre todo sobre ellos mismos, a los que tenían el poder de elegirlos.

La investigación publicada en la revista Palabra Clave de Alberto López y Josefina Vargas (2013), titulada "La política relatada: el Storytelling de Barack Obama en el marco de la Operación Gerónimo", donde se expone que el storytelling surge en los últimos años como una técnica efectiva para que un mensaje, proveniente en este caso de un líder político, logra conquistar el bien más preciado en el mundo de la comunicación actual: el tiempo del ser humano.

Para terminar de introducir y dar un marco teórico a la presente investigación, consideramos importante mencionar que tiene como objetivo principal analizar la percepción del público meta de San Fernando a partir de las tácticas de storytelling empleadas en la campaña de relanzamiento de Los Apellidos del año 2011. De igual manera, tiene como objetivos secundarios describir dichas tácticas de storytelling utilizadas en la campaña, así como comparar el valor de la imagen de marca a partir de ellas, entre las amas de casa y los jóvenes participantes de los focus group realizados. Por lo tanto, el problema 
de investigación es comprender los elementos en las tácticas de storytelling que intervienen en la comunicación de la campaña.

\section{METODOLOGÍA}

El método o estilo de la investigación empleado en el presente trabajo es netamente cualitativo ya que se utilizaron herramientas como una entrevista a profundidad y grupos focales que buscan ahondar en el tema investigado, obteniendo opiniones y percepciones y buscando objetivar los aspectos subjetivos de la conducta humana.

Además, cabe resaltar que este estudio es de tipo analítico ya que busca comprender, aclarar y explicar el fenómeno estudiado, que son las tácticas dentro de la estrategia de storytelling empleadas en la campaña de relanzamiento de San Fernando. Ruiz Olabuénaga, Aristegui y Melgosa (1998) sostienen que en este tipo de investigación el analista adopta una postura crítica, y su interés es el descubrimiento de la verdad con la mayor fiabilidad y validez posibles.

En primer lugar, se ha realizado una entrevista a profundidad a Clarisse Palomino, Coordinadora de Imagen de San Fernando, quien nos ha podido dar una idea más clara acerca de las tácticas de storytelling utilizadas y las motivaciones. Se ha elegido a esta profesional porque se consideró importante conseguir fuentes primarias de información. En esta entrevista se abordaron tanto los objetivos de la campaña de relanzamiento de San Fernando, como las tácticas concretas utilizadas en ella. Esta herramienta nos ayudó a responder al primer objetivo específico que es describir las tácticas de storytelling empleadas en la campaña de Los Apellidos.

Posteriormente, se realizaron 4 focus de entre 8 y 10 miembros cada uno: 2 con amas de casa y 2 con jóvenes entre 20 y 25 años. En los focus se plantaron ejes temáticos 
como rol de los entrevistados con relación a la compra, percepción de la marca San Fernando, recordación de la campaña, percepción de las tácticas de storytelling, percepción de marca antes de la campaña y fidelidad de la marca a partir de estas estrategias en el presente. La subdivisión de focus ayudará al segundo objetivo específico de la investigación que es comparar la imagen de marca entre los padres de familia e hijos.

Se hicieron dos focus por miembro para reducir el sesgo, y poder sacar conclusiones comparando dos grupos diferentes de consumidores. Todas las personas reclutadas para el focus son del público objetivo principal de San Fernando, es decir, del nivel socioeconómico AB. Se elaboró esta segmentación debido a que es un producto de consumo masivo y su target es bastante grande, pero por su distribución y precio se trabajará con personas de ese estatus.

\section{RESULTADOS}

1. Resultados obtenidos de la entrevista a profundidad con Clarisse Palomino, Coordinadora de Imagen de San Fernando

- Objetivos de la campaña de relanzamiento de San Fernando:

- Generar identificación con el consumidor

- Dar el primer paso a la construcción de una lovemark: lograr incluir en el posicionamiento de la marca atributos emocionales, relacionados a valores familiares.

- Aumentar la intención de compra 
- Tácticas de storytelling utilizadas en la campaña:

- Grabación de familias reales en sus propias casas

- Flexibilidad en los guiones

- Dejar la cámara grabando sola por largos minutos

- La utilización de un lenguaje informal

- La convocatoria de familias de diversos niveles socioeconómicos

2. Resultados obtenidos de los focus realizados

- Rol en relación a la compra:

- La mayoría de amas de casa hacen las compras una vez a la semana

- Los jóvenes nunca realizan las compras solos

- Las amas de casa toman la decisión final de compra

- Los jóvenes perciben su opinión como muy importante

- Las amas de casa piden opinión al resto de la familia cuando se sienten inseguras.

- Percepción de la marca San Fernando

- Las amas de casa relacionan la confianza con la marca SF

- Los jóvenes relacionan a San Fernando con sus productos, no con sus atributos

- Las amas de casa personifican a San Fernando como un hombre joven y de carácter bonachón

- Los jóvenes personifican a San Fernando como un pollo o un pavo

- Para las amas de casa la marca es percibida como joven y fresca

- Para los jóvenes es percibida como más antigua de lo que es

- Recordación de la campaña

- La mayoría de las amas de casa recordaba la campaña de Los Apellidos, relacionándola a unión familiar

- La campaña más recordada por los jóvenes era Jueves de Pavita 
- Lo que más recordaban las amas de casa de la campaña eran las vallas y las rimas de las familias con sus gustos alimenticios

- Lo que más recordaban los jóvenes de la campaña eran las redes sociales, seguido por paneles y camiones.

- Percepción de tácticas de storytelling

- Todas las amas de casa resaltan la unión familiar que transmite San Fernando en el spot.

- Los jóvenes resaltan la peruanidad que expresa San Fernando mostrando familias de diferentes estratos socioeconómicos, y la unión familiar.

- Las amas de casa percibieron como positiva la diversidad de familias presentadas en el spot, resaltando que SF era para todas las familias peruanas.

- Los jóvenes se identificaron con las costumbres presentadas por las diferentes familias.

- Todos los jóvenes coincidieron con que percibían naturalidad en las familias del comercial.

- Las amas de casa y jóvenes coinciden en percibir el tono de comunicación como informal y espontáneo

- Percepción de marca antes de la Campaña de Los Apellidos

- Las amas de casa relacionaban a San Fernando solo con pavos

- Los jóvenes relacionaban San Fernando únicamente a la navidad y a los vales que les daban a sus padres para el pavo

- Las amas de casa demostraron dificultad para acordarse de la marca San Fernando antes de la campaña de Los Apellidos

- Todos los jóvenes recuerda la marca San Fernando antes de la campaña

- Algunas amas de casa mencionaron haber empezado a comprar San Fernando porque sus madre lo hacían 
- Fidelidad de la marca a partir de las tácticas de storytelling

- Las amas de casa son consumidoras de San Fernando por motivos más racionales como la calidad y garantía de productos

- Los jóvenes mencionan que son consumidores porque las marca les genera confianza

- Algunos jóvenes comentan que seguirían comprando la marca porque sus padres lo hacen

- Los jóvenes que no realizan las compras ni acompañan a sus padres, tienen más conocimiento de los productos envasados

Focus \#1. Amas de casa

\begin{tabular}{|c|c|c|c|}
\hline $\begin{array}{l}\text { Eje } \\
\text { temático }\end{array}$ & $\begin{array}{l}\text { Pregunt } \\
\text { as }\end{array}$ & Categorías & Nuevas categorías \\
\hline \multirow[t]{3}{*}{$\begin{array}{l}\text { 1. Rol en } \\
\text { relación } \\
\text { a la } \\
\text { compra }\end{array}$} & $\begin{array}{l}1.1 . \\
\text { ¿Con } \\
\text { qué } \\
\text { frecuenc } \\
\text { ia } \\
\text { realizas } \\
\text { las } \\
\text { compras } \\
\text { de la } \\
\text { semana? }\end{array}$ & $\begin{array}{l}\text { 1. 1Frecuencia en las compras } \\
\text { - } 6 \text { de las } 8 \text { participantes realizan las } \\
\text { compras una vez a la semana. } \\
\text { "Los sábados de preferencia, una vez por } \\
\text { semana". Consumidora } 1 \\
\text { "Yo también (una vez a la semana), } \\
\text { religiosamente todos los viernes en la mañana". } \\
\text { Consumidora } 7 \text {. }\end{array}$ & $\begin{array}{l}\text { No hay nuevas } \\
\text { categorías }\end{array}$ \\
\hline & $\begin{array}{l}1.2 \text { ¿Qué } \\
\text { tan } \\
\text { importa } \\
\text { nte es tu } \\
\text { opinión? }\end{array}$ & $\begin{array}{l}\text { 1.2. Valor de opinión sobre las compras } \\
\text { - Todas las amas de casa entrevistadas } \\
\text { toman la decisión. } \\
\text { "Yo porque soy la mamá, mis hijas solo comen". } \\
\text { Consumidora } 4 \\
\text { "Yo también, yo soy la que decido". } \\
\text { Consumidora }\end{array}$ & $\begin{array}{l}\text { No hay nuevas } \\
\text { categorías }\end{array}$ \\
\hline & $\begin{array}{l}\text { 1. 3. iY } \\
\text { la de los } \\
\text { otros } \\
\text { miembr } \\
\text { os de la } \\
\text { familia? }\end{array}$ & $\begin{array}{l}\text { 1.3. Valor de opinión del resto de la familia } \\
\text { - La mayoría de las amas de casa les pide } \\
\text { consejos al resto de la familia } \\
\text { "Le pregunto a mi hija qué desea comer. En base } \\
\text { a eso y si es saludable compro, sino yo decido". } \\
\text { Consumidora } 8 \text {. } \\
\text { "A veces pido una que otra opinión pero la que } \\
\text { decide al final soy yo". Consumidora } 2\end{array}$ & $\begin{array}{l}\text { Les piden consejos } \\
\text { porque les da } \\
\text { pereza } \\
\text { inseguridad tomar } \\
\text { la decisión por ellas } \\
\text { mismas. } \\
\text { "Generalmente un } \\
\text { poco que me da }\end{array}$ \\
\hline
\end{tabular}




\begin{tabular}{|c|c|c|c|}
\hline & & & $\begin{array}{l}\text { pereza pensar yo en } \\
\text { qué } \quad \text { preparar, } \\
\text { porque se me hace } \\
\text { un mundo". } \\
\text { Consumidora } 3\end{array}$ \\
\hline \multirow[t]{3}{*}{$\begin{array}{l}2 . \\
\text { Percepci } \\
\text { ón de la } \\
\text { marca } \\
\text { San } \\
\text { Fernand } \\
\text { o }\end{array}$} & $\begin{array}{l}2.1 \text { ¿Qué } \\
\text { es la } \\
\text { marca } \\
\text { San } \\
\text { Fernand } \\
\text { o para } \\
\text { ustedes? }\end{array}$ & $\begin{array}{l}\text { 2. 1. Significado de la marca San Fernando } \\
\text { - Para el } 50 \% \text { de las entrevistadas San } \\
\text { Fernando es igual a pollos. } \\
\text { "Cuando pienso en San Fernando pienso en } \\
\text { pollos", Consumidora } 2 \text {. } \\
\text { " Para mí es la marca más sonada de pollos... } \\
\text { después los pavos... la navidad."' Consumidora } \\
\text { 4. } \\
\text { - } 3 \text { de las } 8 \text { entrevistadas lo relacionan con } \\
\text { garantía. } \\
\text { "La marca me parece que es buena porque tiene } \\
\text { garantía...' Consumidora } 5 \text {. }\end{array}$ & $\begin{array}{l}\text { No hay nuevas } \\
\text { categorías }\end{array}$ \\
\hline & $\begin{array}{l}2 . \\
2 \text { iCómo } \\
\text { lo } \\
\text { describi } \\
\text { rían si } \\
\text { fuera } \\
\text { una } \\
\text { imagen? }\end{array}$ & $\begin{array}{l}\text { 2. } 2 \text { Descripción de marca equivalente a una } \\
\text { imagen } \\
\text { - El } 50 \% \text { lo relaciona con una imagen } \\
\text { familiar } \\
\text { "Me imagino como una mesa grande en navidad, } \\
\text { con una familia y los productos de San Fernando } \\
\text { en la mesa". Consumidora } 7 . \\
\text { "La imagen sería una familia unida } \\
\text { compartiendo los productos" Consumidora } 2 \text {. }\end{array}$ & $\begin{array}{l}\text { No hay nuevas } \\
\text { categorías }\end{array}$ \\
\hline & $\begin{array}{l}2.3 \text { iY si } \\
\text { fuera } \\
\text { una } \\
\text { persona } \\
?\end{array}$ & $\begin{array}{l}\text { 2.3 Descripción de marca equivalente a una } \\
\text { persona. } \\
\text { • Todas las amas de casa se imaginan a un } \\
\text { hombre } \\
\text { "Como el nombre es Fernando, de hecho tiene } \\
\text { que ser un hombre”. Consumidora } 7 \text {. } \\
\text { “"Yo me imagino un hombre tipo } 40 \text { años" } \\
\text { Consumidora } 8 \text {. } \\
\text { - Las amas de casa lo personifican como } \\
\text { una persona de entre } 25 \text { y } 60 \text { años. } \\
\text { "Puede ser un chef, cocinando, de unos } 30 \\
\text { años." Consumidora } 2 \\
\text { "¡Pechugón! (risas) Algo robusto, de unos } 50 \\
\text { años." Consumidora } 1 \\
\text { - } 3 \text { de las } 8 \text {, lo personifican como un chef, } \\
\text { de carácter alegre }\end{array}$ & $\begin{array}{l}\text { No hay nuevas } \\
\text { categorías }\end{array}$ \\
\hline
\end{tabular}




\begin{tabular}{|c|c|c|c|}
\hline & & $\begin{array}{l}\text { "Bonachón, que le guste la cocina, que le guste } \\
\text { preparar cosas ricas". Consumidora } 6 . \\
\text { "Una persona alegre... como recién salido de la } \\
\text { escuela de cocina". Consumidora } 2 \\
\text { La mayoría lo siente una persona "bonachona" }\end{array}$ & \\
\hline & $\begin{array}{l}2.4 . \\
\text { ¿Saben } \\
\text { cuántos } \\
\text { años } \\
\text { tiene la } \\
\text { empresa } \\
\text { ? }\end{array}$ & $\begin{array}{l}\text { 2.4 Percepción de antigüedad de la marca } \\
\text { - La mayoría calculó } 30 \text { años de } \\
\text { antigüedad de la empresa. }\end{array}$ & $\begin{array}{l}\text { No hay nuevas } \\
\text { categorías }\end{array}$ \\
\hline \multirow[t]{3}{*}{$\begin{array}{l}\text { 3. } \\
\text { Recorda } \\
\text { ción de } \\
\text { la } \\
\text { campañ } \\
\text { a }\end{array}$} & $\begin{array}{l}\text { 3.1 } \\
\text { ¿Recuer } \\
\text { dan } \\
\text { alguna } \\
\text { campañ } \\
\text { a/comun } \\
\text { icación } \\
\text { de la } \\
\text { marca? }\end{array}$ & $\begin{array}{l}\text { 3.1 Recordación de la comunicación de la marca } \\
\text { - } 75 \% \text { de las entrevistadas recordaba la } \\
\text { Campaña de los Apellidos como primera } \\
\text { opción. } \\
\text { "Sí, esa de los Apellidos, que rimaban." } \\
\text { Consumidora } 2 \\
\text { "Esa, creo que es la única, no sé si habrá habido } \\
\text { otra". Consumidora } 3 \\
\text { "La de las familias." Consumidora } 4\end{array}$ & $\begin{array}{l}\text { No hay nuevas } \\
\text { categorías }\end{array}$ \\
\hline & $\begin{array}{l}3.2 \\
\text { ¿Recuer } \\
\text { dan la } \\
\text { campañ } \\
\text { a de los } \\
\text { apellidos } \\
? \quad \text { ¿Qué } \\
\text { decía? }\end{array}$ & $\begin{array}{l}\text { 3.2 Recordación de campaña } \\
\text { - Todas las amas de casa recordaban lo } \\
\text { mismo: la rima de los apellidos con sus } \\
\text { gustos alimenticios } \\
\text { "La rima de los apellidos con alguna comida. } \\
\text { Por ejemplo a los Malaza, les gusta la grasa } \\
\text { (risas). La comunicación decía que había } \\
\text { muchas opciones para preparar, según el gusto } \\
\text { de la gente." Consumidora } 2\end{array}$ & \\
\hline & $\begin{array}{l}3.3 \\
\text { ¿Qué les } \\
\text { gustó o } \\
\text { disgustó } \\
\text { ? ¿Por } \\
\text { qué? }\end{array}$ & $\begin{array}{l}\text { 3.3 Percepción de la campaña } \\
\text { - Las amas de casa daban sus opiniones } \\
\text { mezcladas con respecto a esa campaña y } \\
\text { la de Jueves de Pavita } \\
\text { "Me gustó porque dio una idea de acercamiento } \\
\text { familiar, que todos convergen en una idea y } \\
\text { asocian el día para juntarse a comer esa } \\
\text { pavita... esa idea de unión a la hora de comer me } \\
\text { parece buena". Consumidora } 8 \\
\text { "Gracias a esa publicidad te hacía pensar de por } \\
\text { qué no consumo, si es algo sano." Consumidora } \\
7 \\
\text { "A mí lo que me hacía pensar era que la pavita } \\
\text { era saludable y podías bajar de peso, porque al }\end{array}$ & $\begin{array}{l}\text { Recordación de } \\
\text { acciones de rebote } \\
\text { de la campaña. } \\
\text { "Ah sí, y los memes } \\
\text { de Cristal también, } \\
\text { cuando jugaban } \\
\text { decía: jueves de } \\
\text { pavita., pegó } \\
\text { bastante". Consumidora 1 } \\
\text { "Y las } \\
\text { nutricionistas }\end{array}$ \\
\hline
\end{tabular}




\begin{tabular}{|c|c|c|c|}
\hline & & $\begin{array}{l}\text { papá le decían "esa pancita..." jueves de pavita } \\
\text { para la pancita..." Consumidora } 2\end{array}$ & $\begin{array}{l}\text { también ponen en } \\
\text { los regímenes } \\
\text { alimenticios una } \\
\text { vez a la semana } \\
\text { pavita." } \\
\text { Consumidora } 3\end{array}$ \\
\hline \multirow[t]{3}{*}{$\begin{array}{l}\text { 4. } \\
\text { Percepci } \\
\text { ón de } \\
\text { tácticas } \\
\text { de } \\
\text { storytelli } \\
\text { ng }\end{array}$} & $\begin{array}{l}\text { PASAR } \\
\text { SPOT } \\
\text { 4.1 ¿Qué } \\
\text { piensan } \\
\text { de los } \\
\text { spots? }\end{array}$ & $\begin{array}{l}\text { 4.1 Opinión de los spots } \\
\text { - Todas las entrevistadas relacionaron los } \\
\text { spots con la unión familiar y el consumo } \\
\text { de pollo. } \\
\text { "Desde los estratos más humildes hasta los que } \\
\text { tienen mucha plata, es un alimento muy } \\
\text { importante en la mesa". Consumidora } 2 . \\
\text { "Yo creo que promocionan el pollo porque es un } \\
\text { alimento que está al alcance de todos los niveles, } \\
\text { y bueno, transmite la unión de la familia". } \\
\text { Consumidora } 6 \\
\text { "Es que el pollo está en todas las mesas". } \\
\text { Consumidora } 4\end{array}$ & $\begin{array}{l}\text { Percepción de la } \\
\text { promoción de los } \\
\text { productos de San } \\
\text { Fernando como } \\
\text { algo secundario en } \\
\text { el comercial. } \\
\text { "Yo pienso que San } \\
\text { Fernando ve que el } \\
\text { pueblo peruano es } \\
\text { full emoción, y de } \\
\text { todas maneras nos } \\
\text { emocionamos de } \\
\text { ver a la familia, de } \\
\text { ver todo eso y } \\
\text { bueno de paso } \\
\text { venden ¿no?". } \\
\text { productos, } \\
\text { Consumidora } 2\end{array}$ \\
\hline & $\begin{array}{l}4.2 \quad \text { ¿Si } \\
\text { San } \\
\text { Fernand } \\
\text { o nos } \\
\text { contara } \\
\text { una } \\
\text { historia, } \\
\text { cuál } \\
\text { sería? }\end{array}$ & $\begin{array}{l}\text { 4.2 Historia percibida, contada por San } \\
\text { Fernando. } \\
\text { El } 50 \% \text { relaciona la historia de San Fernando } \\
\text { con reunión familiar. } \\
\text { "San Fernando une a la familia". Consumidora } \\
8 \\
\text { "La historia sería la unión de toda la familia". } \\
\text { Consumidora } 5\end{array}$ & $\begin{array}{l}\text { No hay nuevas } \\
\text { categorías }\end{array}$ \\
\hline & $\begin{array}{l}4.3 \text { ¿Qué } \\
\text { opinan } \\
\text { de las } \\
\text { familias } \\
\text { que } \\
\text { aparece } \\
\text { n en el } \\
\text { comerci } \\
\text { al? }\end{array}$ & $\begin{array}{l}\text { 4.3 Percepción de las familias del comercial } \\
\text { - Todas las amas de casa relacionaron } \\
\text { positivamente la diversidad de las } \\
\text { familias con la peruanidad. } \\
\text { "Variadas, de todo tipo, con diferentes modos de } \\
\text { vida". Consumidora } 2\end{array}$ & $\begin{array}{l}\text { No hay nuevas } \\
\text { categorías }\end{array}$ \\
\hline
\end{tabular}




\begin{tabular}{|c|c|c|c|}
\hline & $\begin{array}{l}4.4 \text { ¿Qué } \\
\text { piensan } \\
\text { del tono } \\
\text { de la } \\
\text { comunic } \\
\text { ación? } \\
\text { ¿Lo } \\
\text { sienten } \\
\text { formal e } \\
\text { informal } \\
\text { ? }\end{array}$ & $\begin{array}{l}\text { 4.4 Percepción del tono de comunicación } \\
\text { - Todas perciben el tono de comunicación } \\
\text { como informal } \\
\text { "Para mí es informal, tiene más llegada, es más } \\
\text { masivo". Consumidora } 8 \\
\text { Relacionan la informalidad con lo familiar } \\
\text { "Tono informal, un tono familiar, con mucho } \\
\text { calor, te contagia, te inmiscuye dentro de algún } \\
\text { grupo". Consumidora } 3\end{array}$ & $\begin{array}{l}\text { No hay nuevas } \\
\text { categorías }\end{array}$ \\
\hline $\begin{array}{l}5 . \\
\text { Percepci } \\
\text { ón de } \\
\text { marca } \\
\text { antes de } \\
\text { la } \\
\text { campañ } \\
\text { a }\end{array}$ & $\begin{array}{l}5.1 \\
\text { ¿Compra } \\
\text { ban SF } \\
\text { antes de } \\
\text { la } \\
\text { campaña } \\
\text { de Los } \\
\text { Apellido } \\
\text { s? }\end{array}$ & $\begin{array}{l}\text { 5.1 Preferencia por San Fernando antes de la } \\
\text { campaña de Los Apellidos. } \\
\text { - La mayoría relaciona San Fernando solo } \\
\text { con los pavos, antes de la campaña. } \\
\text { "San Fernando antes siempre era el pavo, nada } \\
\text { más". Consumidora } 2 \\
\text { "Yo antes de la campaña en diciembre no más, } \\
\text { con los pavos". Consumidora } 4\end{array}$ & $\begin{array}{l}\text { Dificultad para } \\
\text { recordar la relación } \\
\text { con la marca antes } \\
\text { de la campaña. } \\
\text { "Las campañas son } \\
\text { importantes porque } \\
\text { de repente hemos } \\
\text { comprado pero por } \\
\text { comprar... pero ya } \\
\text { cuando escuchas la } \\
\text { campaña como } \\
\text { que... sientes cierto } \\
\text { imán, entonces vas } \\
\text { y compras porque } \\
\text { recuerdas la } \\
\text { propaganda". } \\
\text { Consumidora } 3\end{array}$ \\
\hline $\begin{array}{l}6 . \\
\text { Fidelidad } \\
\text { de la } \\
\text { marca }\end{array}$ & $\begin{array}{l}6.1 \text { ¿Por } \\
\text { qué } \\
\text { motivos } \\
\text { eres } \\
\text { consumi } \\
\text { dor de } \\
\text { San } \\
\text { Fernando } \\
\text { ? }\end{array}$ & $\begin{array}{l}\text { 6. } 1 \text { Motivación de compra de la marca } \\
\text { - La mayoría de amas de casa compran SF } \\
\text { por su calidad y presentación en los } \\
\text { productos } \\
\text { "A mí me parece que su presentación es más } \\
\text { higiénica, las piernas son más gruesas, menos } \\
\text { grasa". Consumidora } 4 \\
\text { "Yo consumo básicamente por la calidad de sus } \\
\text { productos y la diferencia con las otras marcas es } \\
\text { que me parece que San Fernando tiene mucha } \\
\text { más variedad de cosas". Consumidora } 7 \\
\text { "A mi gusta y me atrae comprar San Fernando } \\
\text { por la presentación, me parece mucho más } \\
\text { higiénico y por los cortes y además me parece } \\
\text { que tienen más cuerpo, no los veo flacuchos ni } \\
\text { grasosos". Consumidora } 8\end{array}$ & $\begin{array}{l}\text { No hay nuevas } \\
\text { categorías }\end{array}$ \\
\hline
\end{tabular}


Focus \#2. Amas de Casa

\begin{tabular}{|c|c|c|c|}
\hline $\begin{array}{c}\text { Eje } \\
\text { temático }\end{array}$ & $\begin{array}{c}\text { Pregunta } \\
\text { S }\end{array}$ & Categorías & Nuevas Categorías \\
\hline $\begin{array}{l}\text { 1. Rol en } \\
\text { relación } \\
\text { a la } \\
\text { compra }\end{array}$ & $\begin{array}{l}1 . \\
\text { ¿Con } \\
\text { qué } \\
\text { frecuenc } \\
\text { ia } \\
\text { realizas } \\
\text { las } \\
\text { compras } \\
\text { de la } \\
\text { semana? }\end{array}$ & $\begin{array}{l}\text { 1. 1Frecuencia de compras } \\
\text { - Depende de qué cosa compren las amas } \\
\text { de casa, para definir la frecuencia. } \\
\text { "Por ejemplo, yo voy a un supermercado grande, } \\
\text { voy a Makro y compro ciertas cosas para tres } \\
\text { meses". Consumidora } 1 \\
\text { "Yo las cosas de limpieza y abarrotes una vez al } \\
\text { mes, y las carnes y las verduras semanalmente o } \\
\text { cuando se presenta la ocasión entre semana, } \\
\text { cuando se me antoja algo". Consumidora } 2\end{array}$ & $\begin{array}{lr}\text { Hacer las compras } \\
\text { por salir de la rutina } \\
\text { de la casa } \\
\text { "Y a veces por } \\
\text { distraerme, cuando } \\
\text { no tengo nada que } \\
\text { hacer, voy al } \\
\text { mercado por alguna } \\
\text { verdura o por } \\
\text { alguna cosa. Más } \\
\text { que nada por } \\
\text { caminar". } \\
\text { Consumidora } 1\end{array}$ \\
\hline & $\begin{array}{l}1 . \quad 2 . \\
\text { ¿Qué } \\
\text { tan } \\
\text { importa } \\
\text { nte es tu } \\
\text { opinión } \\
\text { en las } \\
\text { compras } \\
\text { de la } \\
\text { semana? }\end{array}$ & $\begin{array}{l}\text { 1.2. Valor de opinión sobre las compras } \\
\text { - Todas toman la decisión de compra. } \\
\text { Algunas escuchan opiniones, pero al } \\
\text { final ellas tienen la última palabra. } \\
\text { "Yo tomo la decisión pero pido la opinión de } \\
\text { otros". Consumidora } 2 \\
\text { "Yo también decido, consultando a los chicos a } \\
\text { qué hora van a venir a cenar y como nosotros no } \\
\text { tenemos costumbre de comer guardado". } \\
\text { Consumidora } 6 \\
\text { Algunas por falta de tiempo tienen } \\
\text { comida en el congelador que van } \\
\text { sacando según la necesidad. } \\
\text { "Generalmente tengo un poco de todo en el } \\
\text { congelador porque no tengo mucho tiempo. } \\
\text { Entonces cuando me doy esos tiempitos porque } \\
\text { extraño mucho la comida de casa, saco lo que } \\
\text { haya". Consumidora } 4\end{array}$ & $\begin{array}{l}\text { Organización } \\
\text { cambia los fines de } \\
\text { semana. } \\
\text { "Bueno en la } \\
\text { semana, } \\
\text { básicamente decido } \\
\text { yo... salvo el fin de } \\
\text { semana que mi } \\
\text { esposo dice que le } \\
\text { gustaría cocinar } \\
\text { algo, y ahí } \\
\text { compramos } \\
\text { especialmente eso". } \\
\text { Consumidora } 4 \\
\text { "Los domingos que } \\
\text { toca almorzar a la } \\
\text { familia en mi casa } \\
\text { compro lo que ellos }\end{array}$ \\
\hline
\end{tabular}




\begin{tabular}{|c|c|c|c|}
\hline & & $\begin{array}{l}\text { "Normalmente somos dos entonces es más fácil } \\
\text { Agarras un congelado porque lo tengo ya } \\
\text { separado. Entonces, saco lo que voy a necesitar } \\
\text { y es más práctico". Consumidora } 8\end{array}$ & $\begin{array}{l}\text { quieren, y si no } \\
\text { compro para mí y ya } \\
\text { congelo". } \\
\text { Consumidora } 1\end{array}$ \\
\hline \multirow[t]{3}{*}{$\begin{array}{l}2 . \\
\text { Percepci } \\
\text { ón de la } \\
\text { marca } \\
\text { San } \\
\text { Fernand } \\
\text { o }\end{array}$} & $\begin{array}{l}2.1 . \\
\text { ¿Qué es } \\
\text { la marca } \\
\text { San } \\
\text { Fernand } \\
\text { o para } \\
\text { ustedes? }\end{array}$ & $\begin{array}{l}\text { 2.1. Significado de la marca San Fernando } \\
\text { - El 100\% tiene una apreciación positiva } \\
\text { hacia la marca. } \\
\text { "Garantía, limpieza. Para mi San Fernando } \\
\text { siempre... lo consumo bastante". Consumidora } \\
7 \\
\text { "Es cierto, tiene prestigio, peso, confianza. Ya } \\
\text { tienes en tu mente que SF es garantía y compras } \\
\text { sin dudar si quiera que eso va a estar mal". } \\
\text { Consumidora } 8 \\
\text { - Para el } 50 \% \text { de las entrevistadas San } \\
\text { Fernando es garantía } \\
\text { "Para mí es sinónimo de garantía" } \\
\text { Consumidora } 3 \text {. } \\
\text { "Definiría la marca como facilidad y garantía." } \\
\text { Consumidora } 5\end{array}$ & $\begin{array}{l}\text { No hay nuevas } \\
\text { categorías }\end{array}$ \\
\hline & $\begin{array}{l}2.2 \\
\text { ¿Cómo } \\
\text { la } \\
\text { describi } \\
\text { ría si } \\
\text { fuera } \\
\text { una } \\
\text { imagen? }\end{array}$ & $\begin{array}{l}\text { 2. } 2 \text { Descripción de marca equivalente a una } \\
\text { imagen } \\
\text { - Todas las entrevistadas pensaron en una } \\
\text { imagen relacionada a un pollo o un pavo. } \\
\text { "Un pollo entero siendo alimentado con } \\
\text { calidad". Consumidora } 8 \\
\text { "Un pollo limpiecito, fresco". Consumidora } 7 \\
\text { "Un cerdito feliz en medio de un campo verde, } \\
\text { con el sol brillando de un lado". Consumidora } 4\end{array}$ & $\begin{array}{l}\text { No hay nuevas } \\
\text { categorías }\end{array}$ \\
\hline & $\begin{array}{l}2.3 \text { iY si } \\
\text { fuera } \\
\text { una } \\
\text { persona } \\
?\end{array}$ & $\begin{array}{l}\text { 2.3 Descripción de marca equivalente a una } \\
\text { persona. } \\
\text { - Todas las amas de casa se imaginan a un } \\
\text { hombre, entre } 40 \text { y } 60 \text { años. } \\
\text { "Un pata churro, guapo". Consumidora } 7 \\
\text { "Un caballero de unos } 50 \text { años, con mucha } \\
\text { personalidad". Consumidora } 6\end{array}$ & $\begin{array}{l}\text { No hay nuevas } \\
\text { categorías }\end{array}$ \\
\hline
\end{tabular}




\begin{tabular}{|c|c|c|c|c|}
\hline & & $\begin{array}{l}\text { - Todas coinciden en que es un hombre } \\
\text { correcto y de buenos valores. } \\
\text { "Una persona decente, que no te va a engañar, } \\
\text { porque la imagen que proyecta esta persona es } \\
\text { que tiene mucha simpatía contigo". } \\
\text { Consumidora } 8 \\
\text { "Yo me lo imagino exactamente como Papa } \\
\text { Noel pero sin barba". Consumidora } 3\end{array}$ & & \\
\hline & $\begin{array}{l}2.4 . \\
\text { ¿Saben } \\
\text { cuántos } \\
\text { años } \\
\text { tiene la } \\
\text { empresa } \\
\text { ? }\end{array}$ & $\begin{array}{l}\text { 2. } 4 \text { Percepción de antigüedad de la marca } \\
\text { - } 6 \text { de } 8 \text { entrevistadas }(75 \%) \text { sostiene que } \\
\text { la marca tiene } 50 \text { años. }\end{array}$ & $\begin{array}{l}\text { No hay } \\
\text { categorías }\end{array}$ & nuevas \\
\hline & $\begin{array}{l}2.5 \\
\text { ¿Recuer } \\
\text { dan } \\
\text { alguna } \\
\text { campañ } \\
\text { a/comun } \\
\text { icación } \\
\text { de la } \\
\text { marca? }\end{array}$ & $\begin{array}{l}\text { 3.1 Recordación de la comunicación de la marca } \\
\text { - El 50\% no recordaba ninguna } \\
\text { comunicación } \\
\text { - El otro 50\% recordaba campañas } \\
\text { diferentes } \\
\text { "Una que salió hace muchos años, donde el } \\
\text { cerdito estaba durmiendo y le estaban cantando } \\
\text { una canción de cuna, algo así". Consumidora } 5 \\
\text { "Yo me acuerdo de un pavo que estaba en la } \\
\text { televisión para navidad con el logo san Fernando } \\
\text { dorado, que decía que ya venía navidad y que } \\
\text { debíamos ir comprando el pavo". Consumidora } \\
8\end{array}$ & $\begin{array}{l}\text { No hay } \\
\text { categorías }\end{array}$ & nuevas \\
\hline \multirow[t]{2}{*}{$\begin{array}{l}\text { 3. } \\
\text { Recorda } \\
\text { ción de } \\
\text { la } \\
\text { campañ } \\
\text { a }\end{array}$} & $\begin{array}{l}\text { 3.1. } \\
\text { ¿Recuer } \\
\text { dan la } \\
\text { campañ } \\
\text { a de los } \\
\text { apellidos } \\
?\end{array}$ & $\begin{array}{l}\text { 3.1. Recordación de campaña } \\
\text { - El } 75 \% \text { dijo recordar la campaña, pero } \\
\text { cuando se les preguntó acerca de su } \\
\text { contenido solo una lo recordaba. } \\
\text { "Creo que la idea era decir que todas las familias } \\
\text { peruanas consumían SF, sin distinción". } \\
\text { Consumidora } 3\end{array}$ & $\begin{array}{l}\text { No hay } \\
\text { categorías }\end{array}$ & nuevas \\
\hline & $\begin{array}{l}3.2 \text { ¿Qué } \\
\text { les gustó } \\
\text { o } \\
\text { disgustó } \\
\text { ? ¿Por } \\
\text { qué? }\end{array}$ & $\begin{array}{l}\text { 3.2. Percepción de la campaña } \\
\text { • Solo dos la recordaban realmente y sí les } \\
\text { gustó. } \\
\text { "San Fernando siempre hace buenas campañas". } \\
\text { Consumidora } 7\end{array}$ & $\begin{array}{l}\text { No hay } \\
\text { categorías }\end{array}$ & nuevas \\
\hline $\begin{array}{l}4 . \\
\text { Percepci } \\
\text { ón de } \\
\text { tácticas }\end{array}$ & $\begin{array}{l}\text { PASAR } \\
\text { SPOT }\end{array}$ & $\begin{array}{l}\text { 4.1 Opinión de los spots } \\
\text { - Todas se sintieron identificadas y } \\
\text { resaltaron la diversidad de las familias } \\
\text { del comercial. }\end{array}$ & $\begin{array}{l}\text { No hay } \\
\text { categorías }\end{array}$ & nuevas \\
\hline
\end{tabular}




\begin{tabular}{|c|c|c|c|}
\hline $\begin{array}{l}\text { de } \\
\text { storytelli } \\
\text { ng }\end{array}$ & $\begin{array}{l}4.1 \text { ¿Qué } \\
\text { piensan } \\
\text { de los } \\
\text { spots? }\end{array}$ & $\begin{array}{l}\text { "Son diferentes familias, en diferentes } \\
\text { circunstancias". Consumidora } 8 \\
\text { "SF está en todos los estratos, ¿no? Los que } \\
\text { tienen y los que no". Consumidora } 2 \\
\text { "SF es lo que unifica, que sea cual sea el estrato } \\
\text { social es común que se consuma". Consumidora } \\
4\end{array}$ & \\
\hline & $\begin{array}{l}4.2 \quad \text { ¿Si } \\
\text { San } \\
\text { Fernand } \\
\text { o nos } \\
\text { contara } \\
\text { una } \\
\text { historia, } \\
\text { cuál } \\
\text { sería? } \\
\text { Poner } \\
\text { ejemplos } \\
\text { primero } \\
\text { : Coca } \\
\text { Cola, } \\
\text { Dove, } \\
\text { Lego. }\end{array}$ & $\begin{array}{l}\text { 4. } 2 \text { Historia percibida, contada por San } \\
\text { Fernando. } \\
\text { - } 7 \text { de } 8 \text { amas de casa relacionaron la unión } \\
\text { familiar a la historia que cuenta SF. } \\
\text { "Una familia unida compartiendo los } \\
\text { alimentos. La familia busca un motivo para } \\
\text { compartir y ofrecer algo rico". Consumidora } 2 \\
\text { "La unión de la familia peruana. Como que } \\
\text { estás unido mientras consumas SF". } \\
\text { Consumidora } 4 \\
\text { "Que SF a través de los años unifica a la familia } \\
\text { y se consume de generación en generación". } \\
\text { Consumidora } 6\end{array}$ & $\begin{array}{l}\text { No hay nuevas } \\
\text { categorías }\end{array}$ \\
\hline & $\begin{array}{l}4.3 \text { ¿Qué } \\
\text { opinan } \\
\text { de las } \\
\text { familias } \\
\text { que } \\
\text { aparecen } \\
\text { en el } \\
\text { comercia } \\
1 ? \text { ¿Qué } \\
\text { imagen } \\
\text { le dan a } \\
\text { la marca? }\end{array}$ & $\begin{array}{l}\text { 4.3 Percepción de las familias del comercial } \\
\text { - Todas las amas de casa relacionaron la } \\
\text { diversidad de las familias del comercial } \\
\text { con el alcance de SF para llegar a todos } \\
\text { los sectores socioeconómicos. } \\
\text { "Que es para el paladar del rico y del pobre". } \\
\text { Consumidora } 2 \\
\text { "Que hay una gran variedad de productos, para } \\
\text { diferentes sectores". Consumidora } 1 \\
\text { "El mensaje de la publicidad abarca que todos } \\
\text { los estratos socioeconómicos consumen SDF, } \\
\text { que llega a todas las mesas". Consumidora } 6\end{array}$ & $\begin{array}{l}\text { No hay nuevas } \\
\text { categorías }\end{array}$ \\
\hline & $\begin{array}{l}4.4 \text { ¿Qué } \\
\text { piensan } \\
\text { del tono } \\
\text { de la } \\
\text { comunic } \\
\text { ación? } \\
\text { ¿Lo }\end{array}$ & $\begin{array}{l}\text { 4.4 Percepción del tono de comunicación } \\
\text { - La mayoría de las amas de casa perciben } \\
\text { la comunicación como informal y } \\
\text { relacionan la informalidad con la } \\
\text { naturalidad. }\end{array}$ & $\begin{array}{l}\text { No hay nuevas } \\
\text { categorías }\end{array}$ \\
\hline
\end{tabular}




\begin{tabular}{|c|c|c|c|}
\hline & $\begin{array}{l}\text { sienten } \\
\text { formal e } \\
\text { informal } \\
? \quad \text { ¿Eso } \\
\text { qué les } \\
\text { hace } \\
\text { sentir? }\end{array}$ & $\begin{array}{l}\text { "Informal y que convence, se ve tan espontáneo } \\
\text { que se ve a las familias disfrutando de la comida, } \\
\text { en diferentes mesas pero cada uno disfruta". } \\
\text { Consumidora } 2 \\
\text { "Natural, tal cual es". Consumidora } 6 \\
\text { - La mayoría de amas de casa relacionan } \\
\text { la informalidad de la comunicación con } \\
\text { la espontaneidad de las familias. } \\
\text { "Quizás no sea la informal la palabra sino } \\
\text { natural, porque las familias se manifiestan de } \\
\text { manera natural, espontánea, cada uno en su } \\
\text { mesa... todos disfrutando". Consumidora } 2 \\
\text { "Siento que es lo que realmente pasa en tu hogar, } \\
\text { es la imagen que proyecta cada una de las } \\
\text { familias". Consumidora } 3\end{array}$ & \\
\hline $\begin{array}{l}5 . \\
\text { Percepci } \\
\text { ón de } \\
\text { marca } \\
\text { antes de } \\
\text { la } \\
\text { campañ } \\
\text { a }\end{array}$ & $\begin{array}{l}5.1 \\
\text { ¿Compr } \\
\text { aban SF } \\
\text { antes de } \\
\text { la } \\
\text { campañ } \\
\text { a de Los } \\
\text { Apellido } \\
\text { s o } \\
\text { prefería } \\
\text { n alguna } \\
\text { otra } \\
\text { marca? }\end{array}$ & $\begin{array}{l}\text { - Todas las amas de casa ya compraban } \\
\text { San Fernando desde antes de la campaña } \\
\text { "Yo siempre he comprado San Fernando. Hay } \\
\text { una marca Redondos que un día la compré pero } \\
\text { no me convencía mucho el color de la piel del } \\
\text { pollo". Consumidora } 8 \\
\text { "Esta campaña no cambió mucho, siempre } \\
\text { compraba". Consumidora } 5 \\
\text { "Sí compraba antes, no solo pollo, sino también } \\
\text { los embutidos sino el pollo, la pavita y los } \\
\text { utilizaba bastante en las loncheras de mis hijas". } \\
\text { Consumidora }\end{array}$ & $\begin{array}{l}2 \text { de las amas de } \\
\text { casa, dicen haber } \\
\text { empezado } \\
\text { comprar an } \\
\text { Fernando porque } \\
\text { sus madres lo } \\
\text { hacían. } \\
\text { "Mi } \\
\text { compraba SF, } \\
\text { entonces fue como } \\
\text { una cosa natural } \\
\text { para mi, nunca me } \\
\text { hice la preguntado } \\
\text { dije "ya bueno, } \\
\text { calidad". } \\
\text { Consumidora } 4 \\
\text { "Yo también, desde } \\
\text { que le pregunté a mi } \\
\text { mami qué marca era } \\
\text { buena, yo solo me } \\
\text { acuerdo la marca } \\
\text { San Fernando". } \\
\text { Consumidora } 3 \\
2 \text { de las amas de } \\
\text { casa, dijeron haber } \\
\text { vivido en } \\
\text { anteriormente }\end{array}$ \\
\hline
\end{tabular}




\begin{tabular}{|c|c|c|c|}
\hline & & & $\begin{array}{l}\text { provincia y que en } \\
\text { esas circunstancias } \\
\text { no queda otra } \\
\text { opción que comprar } \\
\text { lo que hay en el } \\
\text { mercado. } \\
\text { "Claro, yo también } \\
\text { vivía en provincia } \\
\text { entonces tenías que } \\
\text { comprar sí o sí el } \\
\text { pollo del mercado". } \\
\text { Consumidora } 5\end{array}$ \\
\hline $\begin{array}{l}6 . \\
\text { Fidelidad } \\
\text { de la } \\
\text { marca }\end{array}$ & $\begin{array}{l}6.1 \text { ¿Por } \\
\text { qué } \\
\text { motivos } \\
\text { eres } \\
\text { consumi } \\
\text { dor de } \\
\text { San } \\
\text { Fernand } \\
\text { o? }\end{array}$ & $\begin{array}{l}\text { 6. 1. Motivación de compra de la marca } \\
\text { - La cualidad más mencionada por las } \\
\text { amas de casa fue la calidad, seguida por } \\
\text { la garantía y la facilidad en la } \\
\text { preparación. } \\
\text { "Porque no vamos a ser engañados en la compra, } \\
\text { es sinónimo de garantía". Consumidora } 4 \\
\text { "Yo por su calidad y por la variedad, por la } \\
\text { seguridad cuando compro el chancho". } \\
\text { Consumidora } 5 \\
\text { "Porque son productos frescos y de calidad, de } \\
\text { fácil acceso, también por las formas en las que } \\
\text { están ya cortados". Consumidora } 2 \\
\text { - Las dos ventajas más mencionadas } \\
\text { fueron la buena distribución y la } \\
\text { variedad de productos } \\
\text { "Tiene todos los requisitos y hay mucha } \\
\text { facilidad para adquirirlo". Consumidora } 6 \\
\text { "Es un producto que lo encuentras fácil, a donde } \\
\text { vas hay". Consumidora } 7 \\
\text { "La variedad en los tres productos principales } \\
\text { que son el pollo, el chancho y el pavo". } \\
\text { Consumidor }\end{array}$ & $\begin{array}{l}\text { No hay nuevas } \\
\text { categorías }\end{array}$ \\
\hline
\end{tabular}

Focus \#3. Jóvenes 


\begin{tabular}{|c|c|c|c|}
\hline $\begin{array}{c}\text { Eje } \\
\text { temático }\end{array}$ & $\begin{array}{l}\text { Pregunt } \\
\text { as }\end{array}$ & Categorías & Nuevas categorías \\
\hline $\begin{array}{l}\text { 1. Rol en } \\
\text { relación } \\
\text { a la } \\
\text { compra }\end{array}$ & $\begin{array}{l}\text { 1. } \\
\text { ¿Con } \\
\text { qué } \\
\text { frecuenc } \\
\text { ia } \\
\text { realizas } \\
\text { las } \\
\text { compras } \\
\text { de la } \\
\text { casa? }\end{array}$ & $\begin{array}{l}\text { 1.1 Frecuencia de compras } \\
\text { - Con excepción de una, ninguno de los } \\
\text { jóvenes entrevistados realiza las } \\
\text { compras de su casa de manera } \\
\text { independiente. } \\
\text { "A la semana no, mis viejos compran al mes y a } \\
\text { veces los acompaño". Joven } 1 \\
\text { "En mi casa compran cada quince días pero casi } \\
\text { nunca acompaño". Joven } 8 \\
\text { - Los jóvenes dicen acompañar a sus } \\
\text { padres a hacer las compras muy } \\
\text { esporádicamente } \\
\text { "En mi casa mi mamá hace semanal y yo la } \\
\text { acompaño muy rara vez". Joven } 6\end{array}$ & $\begin{array}{l}\text { No hay nuevas } \\
\text { categorías }\end{array}$ \\
\hline & $\begin{array}{l}\text { 1. } 2 . \\
\text { ¿Qué } \\
\text { tan } \\
\text { importa } \\
\text { nte es tu } \\
\text { opinión } \\
\text { en las } \\
\text { compras } \\
\text { de la } \\
\text { semana? }\end{array}$ & $\begin{array}{l}\text { 1.2 Valor de opinión sobre las compras } \\
\text { - La mayoría de jóvenes percibe su } \\
\text { opinión como importante } \\
\text { "En mi caso mi opinión es súper importante, de } \\
\text { hecho siempre nos preguntan "qué tal, les } \\
\text { gustó?"'. Joven } 2 \\
\text { "Siempre me preguntan "qué quieres, qué } \\
\text { necesitas", mi opinión es súper importante". } \\
\text { Joven } 3\end{array}$ & $\begin{array}{l}\text { Algunos jóvenes no } \\
\text { consideran } \\
\text { necesario que se les } \\
\text { pregunte su opinión } \\
\text { porque consideran } \\
\text { que sus mamás ya } \\
\text { conocen sus gustos } \\
\text { "A mí también } \\
\text { siempre me } \\
\text { pregunta mi mamá, } \\
\text { y cuando no lo hace } \\
\text { siempre compra lo } \\
\text { que nos gusta } \\
\text { porque ya conoce } \\
\text { nuestros gustos". } \\
\text { Joven } 6 \\
\text { "A mí no me } \\
\text { preguntan, ella ya } \\
\text { sabe mis gustos". } \\
\text { Joven } 9\end{array}$ \\
\hline $\begin{array}{l}2 . \\
\text { Percepci } \\
\text { ón de la } \\
\text { marca } \\
\text { San }\end{array}$ & $\begin{array}{l}2 . \quad 1 . \\
\text { ¿Qué es } \\
\text { la marca } \\
\text { San } \\
\text { Fernand }\end{array}$ & $\begin{array}{l}\text { 2. 1. Significado de la marca San Fernando } \\
\text { - La mitad de los entrevistados relacionan } \\
\text { la marca con sus productos como el pollo } \\
\text { o el pavo y la otra mitad la relaciona con } \\
\text { calidad }\end{array}$ & \begin{tabular}{lr}
\multicolumn{2}{l}{ Los jóvenes tienden } \\
a relacionar \\
marca & San \\
Fernando con & sus
\end{tabular} \\
\hline
\end{tabular}




\begin{tabular}{|c|c|c|c|}
\hline $\begin{array}{l}\text { Fernand } \\
\text { o }\end{array}$ & $\begin{array}{l}\text { o para } \\
\text { ustedes? }\end{array}$ & $\begin{array}{l}\text { "Mmmm.. yo la puedo asociar con lo que come } \\
\text { uno de comida casera, de hecho siempre la } \\
\text { tienes en cuenta en alguna de las comidas que } \\
\text { haces en la casa". Joven } 5 \\
\text { "Si dices San Fernando rápidamente te viene a } \\
\text { la mente calidad". Joven } 9 \\
\text { "Mi carne favorita es el pollo, entonces sí es } \\
\text { cierto que la primera marca en la que pienso } \\
\text { cuando voy a comprar algo de pollo es San } \\
\text { Fernando, y me genera confianza". Joven } 3\end{array}$ & $\begin{array}{l}\text { productos de } \\
\text { comida rápida. No } \\
\text { saben si el pollo que } \\
\text { se consume en casa } \\
\text { es San Fernando } \\
\text { "No te podría decir } \\
\text { qué cosa } \\
\text { exactamente de } \\
\text { compramos per } \\
\text { ellos, podrían ser } \\
\text { los nuggets y las } \\
\text { latas de pollo". } \\
\text { Joven } 2 \text { se } \\
\text { "No me fijo si el } \\
\text { pollo es San } \\
\text { Fernando, pero sí } \\
\text { los embutidos". } \\
\text { Joven } 8 \\
\text { - Uno de los } \\
\text { primeros } \\
\text { productos } \\
\text { que re } \\
\text { relacionan } \\
\text { con San } \\
\text { Fernando es } \\
\text { el pollo } \\
\text { "El atún de pollo es } \\
\text { lo mejor que han } \\
\text { inventado, es } \\
\text { buenaso" Joven } 5\end{array}$ \\
\hline & $\begin{array}{l}2 . \\
\text { ¿Cómo } \\
\text { lo } \\
\text { describi } \\
\text { rían si } \\
\text { fuera } \\
\text { una } \\
\text { imagen? }\end{array}$ & $\begin{array}{l}\text { 2. } 2 \text { Descripción de marca equivalente a una } \\
\text { imagen } \\
\text { - Todos los jóvenes tienen una imagen } \\
\text { mental de los productos de San } \\
\text { Fernando: pollo o chancho } \\
\text { "Yo pienso en pollo cuando me dices San } \\
\text { Fernando pero también me imaginé el } \\
\text { chanchito". Joven } 7 \\
\text { "Un pollo rosado que está listo para cortar". } \\
\text { Joven } 3\end{array}$ & $\begin{array}{l}\text { No hay nuevas } \\
\text { categorías }\end{array}$ \\
\hline
\end{tabular}




\begin{tabular}{|c|c|c|c|}
\hline & & $\begin{array}{l}\text { - Todos los entrevistados coincidieron en } \\
\text { que si le tenían que poner un fondo a la } \\
\text { imagen, sería azul. }\end{array}$ & \\
\hline & $\begin{array}{l}2.3 \text { iY si } \\
\text { fuera } \\
\text { una } \\
\text { persona } \\
?\end{array}$ & $\begin{array}{l}\text { 2.3 Descripción de marca equivalente a una } \\
\text { persona. } \\
\text { - La mayoría de los jóvenes entrevistados } \\
\text { personifican a la marca como un hombre } \\
\text { de entre } 50 \text { y } 60 \text { años, de personalidad } \\
\text { amable } \\
\text { "Hombre gordo, con barba, con gorro de chef, } \\
\text { con sus bigotitos, estatura promedio, alegre". } \\
\text { Joven } 9 \\
\text { "Igual, abuelo, como el capataz de Toy Story } \\
\text { pero con un machete en la mano, que da ganas } \\
\text { de abrazar, amable". Joven } 6\end{array}$ & $\begin{array}{l}\text { No hay nuevas } \\
\text { categorías }\end{array}$ \\
\hline & $\begin{array}{l}2.4 \\
\text { ¿Saben } \\
\text { cuántos } \\
\text { años } \\
\text { tiene la } \\
\text { empresa } \\
?\end{array}$ & $\begin{array}{l}\text { 2.4 Percepción de antigüedad de la marca } \\
\text { • La mayoría percibe a San Fernando } \\
\text { como una marca mucho más antigua de } \\
\text { lo que es. } \\
\text { "Yo le pongo por lo menos } 85 \text { ". Joven } 8 \\
\text { "Más de } 100 \text { " Joven } 6 \\
\text { "No sé, 150". Joven } 3\end{array}$ & $\begin{array}{l}\text { No hay nuevas } \\
\text { categorías }\end{array}$ \\
\hline \multirow[t]{2}{*}{$\begin{array}{l}3 . \\
\text { Recordac } \\
\text { ión de } \\
\text { campaña }\end{array}$} & $\begin{array}{l}3.1 \\
\text { ¿Recuer } \\
\text { dan } \\
\text { alguna } \\
\text { campañ } \\
\text { a/comun } \\
\text { icación } \\
\text { de la } \\
\text { marca? }\end{array}$ & $\begin{array}{l}\text { 3.1 Recordación de la comunicación de la marca } \\
\text { - El comercial más recordado por los } \\
\text { jóvenes es Jueves de Pavita } \\
\text { - Solo una persona recordaba la campaña } \\
\text { de Los Apellidos. }\end{array}$ & $\begin{array}{l}\text { Algunos jóvenes } \\
\text { recuerdan el } \\
\text { comercial de Así } \\
\text { los criamos en SF, } \\
\text { porque fue usado } \\
\text { como broma para } \\
\text { sus amigos que } \\
\text { estaban subidos de } \\
\text { peso }\end{array}$ \\
\hline & $\begin{array}{l}3.2 \\
\text { ¿Recuer } \\
\text { dan la } \\
\text { campañ } \\
\text { a de los } \\
\text { apellidos } \\
? \text { ¿Qué } \\
\text { decía? }\end{array}$ & $\begin{array}{l}\text { 3.2. Recordación de campaña } \\
\text { - Lo que más recordaban los jóvenes de la } \\
\text { campaña eran las redes sociales, seguido } \\
\text { por los paneles y camiones con los } \\
\text { apellidos. } \\
\text { "Ponían, no sé, Los Castillo... me acuerdo los } \\
\text { paneles grandes y que la gente se empezó a } \\
\text { emocionar y que buscaba su apellido en redes } \\
\text { sociales". Joven } 9 \\
\text { "Yo me acuerdo que vi } 5 \text { mil apellidos en } \\
\text { camiones por todo Lima, pero nunca vi el mio... }\end{array}$ & $\begin{array}{l}\text { A la mayoría de } \\
\text { jóvenes les llamó la } \\
\text { atención la } \\
\text { interacción que } \\
\text { generó la campaña } \\
\text { en las redes sociales } \\
\text { "Yo me acuerdo } \\
\text { que la gente usaba } \\
\text { su apellido como } \\
\text { loca y si, por }\end{array}$ \\
\hline
\end{tabular}




\begin{tabular}{|c|c|c|c|}
\hline & & $\begin{array}{l}\text { también me acuerdo que hubo gente que subía } \\
\text { en Facebook y se etiquetaban toditos". Joven } 8\end{array}$ & $\begin{array}{l}\text { ejemplo, yo veía tu } \\
\text { apellido, le tomaba } \\
\text { foto con mi celular } \\
\text { y lo publicaba. Es } \\
\text { más, como que la } \\
\text { gente se hacía } \\
\text { medio cómplice". } \\
\text { Joven } 5\end{array}$ \\
\hline & $\begin{array}{l}3.3 \text { ¿Qué } \\
\text { les gustó } \\
\text { o } \\
\text { disgustó } \\
\text { ? ¿Por } \\
\text { qué? }\end{array}$ & $\begin{array}{l}\text { 3.3 Percepción de la campaña } \\
\text { - En términos generales la campaña sí } \\
\text { agradó a los jóvenes, pero no sintieron } \\
\text { que fue expresamente dirigida a ellos } \\
\text { "Sí me gustó pero rápidamente lo olvidé... } \\
\text { porque yo no soy de ir a comprar San Fernando". } \\
\text { Joven } 9 \\
\text { "Ahorita me acabo de dar cuenta que sí el apego } \\
\text { fue demasiado fuerte... y sobre todo se logró } \\
\text { gente mayor, porque no creo que nosotros } \\
\text { seamos el target". Joven } 8 \\
\text { - La mayoría considera interesante la } \\
\text { campaña, pero en cuanto a redes } \\
\text { sociales, sintió que duró mucho, hasta el } \\
\text { punto de aburrir. } \\
\text { "Sí, si me gustó pero llegó un momento en que } \\
\text { ya me aburrió. Al principio era como que "ah ya } \\
\text { qué divertido" y buscabas pero luego ya era } \\
\text { como que me aburrió porque todo el mundo } \\
\text { empezó a subir fotos de los apellidos de todos } \\
\text { lados". Joven } 5\end{array}$ & $\begin{array}{l}3 \text { jóvenes } \\
\text { mencionaron que } \\
\text { no sintieron mucha } \\
\text { identificación con } \\
\text { la marca desde el } \\
\text { comienzo porque } \\
\text { pensaban que no } \\
\text { iban a encontrar su } \\
\text { apellido. } \\
\text { “ }\end{array}$ \\
\hline $\begin{array}{l}4 . \\
\text { Percepci } \\
\text { ón de las } \\
\text { tácticas } \\
\text { de } \\
\text { storytelli } \\
\text { ng. }\end{array}$ & $\begin{array}{l}\text { PASAR } \\
\text { SPOT } \\
4.1 \text { ¿Qué } \\
\text { piensan } \\
\text { de los } \\
\text { spots? }\end{array}$ & $\begin{array}{l}\text { 4.1 Opinión de los spots } \\
\text { - Todos los entrevistados resaltaron la } \\
\text { peruanidad que busca destacar San } \\
\text { Fernando mediante los spots } \\
\text { "La verdad la propaganda me parece bien } \\
\text { emotiva por la música y por cómo habla... y me } \\
\text { parece bien integradora porque describe } \\
\text { bastante la realidad peruana que tenemos mucho } \\
\text { contraste". Joven } 7 \\
\text { "Creo que lo que marca mucho es la diversidad } \\
\text { del Perú, diferentes sociedades, diferentes } \\
\text { apellidos". Joven } 9\end{array}$ & $\begin{array}{l}\text { No hay nuevas } \\
\text { categorías }\end{array}$ \\
\hline
\end{tabular}




\begin{tabular}{|c|c|c|}
\hline $\begin{array}{l}4.2 \quad \text { iSi } \\
\text { San } \\
\text { Fernand } \\
\text { o nos } \\
\text { contara } \\
\text { una } \\
\text { historia, } \\
\text { cuál } \\
\text { sería? }\end{array}$ & $\begin{array}{l}\text { - } 3 \text { entrevistados sostienen que la sola } \\
\text { mención de la comida ya tiene relación } \\
\text { con peruanidad } \\
\text { “...al peruano por el estómago lo ganas de todas } \\
\text { maneras". Joven } 5 \\
\text { "que al peruano le dices comida y de frente saca } \\
\text { el pecho". Joven } 8 \\
\text { - Todos los jóvenes coincidieron en que } \\
\text { el comercial apela a lo emotivo } \\
\text { "Sí me pareció muy emotivo y siento que } \\
\text { identifica a todos y da a entender que las familias } \\
\text { no son como mamá, hijo, papá sino que es donde } \\
\text { haya unión y amor". Joven } 6 \\
\text { "La verdad la propaganda me parece bien } \\
\text { emotiva por la música y por cómo habla". Joven } \\
7 \\
\text { "La integración y la interculturalidad son las } \\
\text { ideas principales, es emotivo porque las } \\
\text { imágenes están bien respaldadas en el discurso". } \\
\text { Joven } 3 \\
\text { 4. } 2 \text { Historia percibida, contada por San } \\
\text { Fernando. } \\
\text { - Todos los jóvenes relacionaron la } \\
\text { historia que cuenta SF con la unión } \\
\text { familiar } \\
\text { "Es como si dijeran: "los productos son un } \\
\text { pretexto, lo que nosotros queremos es que se una } \\
\text { la familia”". Joven } 1 \\
\text { "Que una simple comida, te da unión familiar y } \\
\text { anécdotas". Joven } 9 \\
\text { "El producto que te da SF es la décima parte de } \\
\text { todo lo que te puede ofrecer la marca, que da } \\
\text { unión familiar, qué es algo más que solamente la } \\
\text { comida que te vas a comer". Joven } 7\end{array}$ & \\
\hline $\begin{array}{l}4.3 \text { ¿Qué } \\
\text { piensan } \\
\text { de las } \\
\text { familias } \\
\text { del }\end{array}$ & $\begin{array}{l}\text { 4.3 Percepción de las familias del comercial } \\
\text { - Todos demostraron } \\
\text { identificados con las costumbres } \\
\text { mostradas en el comercial y lo }\end{array}$ & $\begin{array}{l}\text { Todos coinciden } \\
\text { que el papel del } \\
\text { comercial }\end{array}$ \\
\hline
\end{tabular}




\begin{tabular}{|c|c|c|}
\hline $\begin{array}{l}\text { comerci } \\
\text { al? }\end{array}$ & $\begin{array}{l}\text { relacionaron con peruanidad y } \\
\text { diversidad. } \\
\text { "Que no importa si te vas a comer un pollo a la } \\
\text { brasa o pollo sancochado, que SF está ahí, es } \\
\text { para todos". Joven } 7 \\
\text { "Que es una marca cálida, cercana y peruana". } \\
\text { Joven } 3 \\
\text { "Sí, sobre todo eso porque no creo que un } \\
\text { europeo vea eso y se sienta identificado...". } \\
\text { Joven } 6 \\
\text { - Todos están de acuerdo con que las } \\
\text { familias no parecen ser actuadas y eso } \\
\text { les da una sensación de realidad. } \\
\text { "Claro, si no lo has visto en tu casa lo has visto } \\
\text { en alguna familia". Joven } 7 \\
\text { "Además, es eso que vez y dices "no es } \\
\text { actuado". Joven } 8 \\
\text { "Utiliza comportamientos realistas, le meten el } \\
\text { codo a la mesa...” Joven } 9 \\
\text { "Es más, ¡hay gente que tapa la cámara con la } \\
\text { espalda!". Joven } 7 \\
\text { "Siento que han ido a la casa de una de las } \\
\text { familias, han puesto la cámara y han fluido.". } \\
\text { Joven } 6 \\
\text { "Por lo mismo que es espontáneo te busca } \\
\text { emocionar, sientes como si en verdad estuviera } \\
\text { pasando y te identificas bastante”. Joven } 1\end{array}$ & 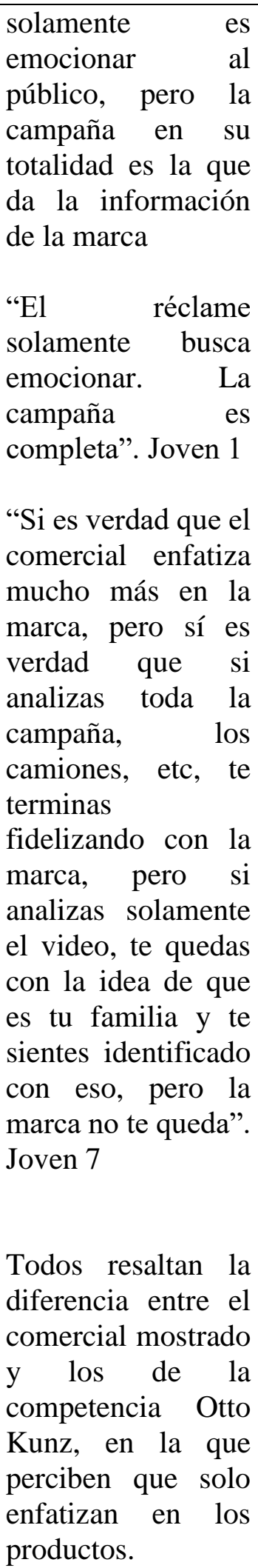 \\
\hline
\end{tabular}




\begin{tabular}{|c|c|c|c|}
\hline & & & $\begin{array}{l}\text { "Comparándolo } \\
\text { con los comerciales } \\
\text { de Otto Kunz por } \\
\text { ejemplo, ahí lo } \\
\text { primero es el } \\
\text { jamón, el sabor, el } \\
\text { humo, a las justas } \\
\text { vez al broder } \\
\text { comiendo". Joven } 6\end{array}$ \\
\hline & $\begin{array}{l}4.4 \text { ¿Qué } \\
\text { piensan } \\
\text { del tono } \\
\text { de la } \\
\text { comunic } \\
\text { ación? } \\
\text { ¿lo } \\
\text { sienten } \\
\text { formal o } \\
\text { informal } \\
\text { ? }\end{array}$ & $\begin{array}{l}\text { 4.4 Percepción del tono de comunicación } \\
\text { - Los jóvenes consideran que es un tono } \\
\text { de comunicación más natural, pero lo } \\
\text { relacionan un poco más con lo informal, } \\
\text { que con lo formal. } \\
\text { "Tono de comunicación informal pero no llega } \\
\text { a lo que es el chabacano". Joven } 3 \\
\text { "Podría ser informal porque siento que me } \\
\text { tutea". Joven } 7 \\
\text { "Neutral, le ha dado uno en el medio, para que } \\
\text { le caiga a todos los niveles socioeconómicos". } \\
\text { Joven } 5\end{array}$ & $\begin{array}{l}\text { No hay nuevas } \\
\text { categorías }\end{array}$ \\
\hline $\begin{array}{l}5 . \\
\text { Percepci } \\
\text { ón de } \\
\text { marca } \\
\text { antes de } \\
\text { la } \\
\text { campañ } \\
\text { a }\end{array}$ & $\begin{array}{l}5.1 \\
\text { ¿Recuer } \\
\text { dan } \\
\text { haber } \\
\text { compra } \\
\text { do San } \\
\text { Fernand } \\
\text { o antes } \\
\text { de esta } \\
\text { campañ } \\
\text { a? }\end{array}$ & $\begin{array}{l}\text { 5. 1. Preferencia por San Fernando antes de la } \\
\text { campaña de Los Apellidos. } \\
\text { - Todos los jóvenes recuerdan haber } \\
\text { comprado SF antes de la campaña }\end{array}$ & $\begin{array}{l}\text { No hay nuevas } \\
\text { categorías }\end{array}$ \\
\hline $\begin{array}{l}6 . \\
\text { Fidelida } \\
\text { d de } \\
\text { marca }\end{array}$ & $\begin{array}{l}\text { 6.1 ¿Por } \\
\text { qué se } \\
\text { consider } \\
\text { an } \\
\text { consumi } \\
\text { dores de } \\
\text { SF? }\end{array}$ & $\begin{array}{l}\text { 6.1 Motivación de compra de la marca } \\
\text { - El } 50 \% \text { de los jóvenes mencionaron que } \\
\text { comprarían San Fernando porque sus } \\
\text { padres lo hacen } \\
\text { "Porque mi mamá los compra y cuando yo he } \\
\text { comprado porque pienso en la calidad". Joven } 6 \\
\text { "Yo voluntariamente no he comprado ningún } \\
\text { producto, los consumo porque están en mi casa". } \\
\text { Joven } 2\end{array}$ & $\begin{array}{l}\text { No hay nuevas } \\
\text { categorías }\end{array}$ \\
\hline
\end{tabular}




\begin{tabular}{|l|l|}
\hline Los que mencionan sí haber comprado \\
San Fernando, dicen hacerlo porque la \\
perciben como una marca de confianza \\
"Porque pienso que es más fácil, si es una marca \\
reconocida, de confianza, ya no tienes el trabajo \\
de preocuparte de la responsabilidad de tu \\
salud". Joven 7 \\
"Por calidad y porque está muy posicionado en \\
la mente del consumidor. Y considero que es el \\
líder". Joven 9
\end{tabular} \mid

Focus \#4. Jóvenes

\begin{tabular}{|c|c|c|c|}
\hline $\begin{array}{c}\text { Eje } \\
\text { temático }\end{array}$ & $\begin{array}{l}\text { Pregunt } \\
\text { as } \\
\end{array}$ & Categorías & Nuevas categorías \\
\hline $\begin{array}{l}\text { 1. Rol en } \\
\text { relación } \\
\text { a la } \\
\text { compra }\end{array}$ & $\begin{array}{l}\text { 1. } 1 \\
\text { ¿Con } \\
\text { qué } \\
\text { frecuenc } \\
\text { ia } \\
\text { realizas } \\
\text { las } \\
\text { compras } \\
\text { de la } \\
\text { casa? }\end{array}$ & $\begin{array}{l}\text { 1. } 1 \text { Frecuencia de compras } \\
\text { - Con excepción de dos, ninguno de los } \\
\text { jóvenes entrevistados realiza las } \\
\text { compras de su casa de manera } \\
\text { independiente. } \\
\text { "Las compras las hacen mis papás, creo que una } \\
\text { vez al mes". Joven } 3 \\
\text { "Participo muy esporádicamente, cuando yo } \\
\text { estoy en el carro y tenemos que parar". Joven } 4 \\
\text { - Algunos jóvenes dicen acompañar a sus } \\
\text { padres a hacer las compras muy } \\
\text { esporádicamente } \\
\text { "Cuando tenía tiempo iba tipo } 3 \text { veces al mes". } \\
\text { Joven } 5\end{array}$ & $\begin{array}{l}\text { No hay nuevas } \\
\text { categorías }\end{array}$ \\
\hline & $\begin{array}{l}1.2 \text { ¿Qué } \\
\text { tan } \\
\text { importa } \\
\text { nte es tu } \\
\text { opinión } \\
\text { en las } \\
\text { compras } \\
\text { de la } \\
\text { casa? }\end{array}$ & $\begin{array}{l}\text { 1.2 Valor de opinión sobre las compras } \\
\text { - La mayoría de jóvenes percibe su } \\
\text { opinión como importante } \\
\text { "Sí me preguntan qué quiero comer, según mi } \\
\text { ritmo rápido de vida". Joven } 2 \\
\text { - La mitad de jóvenes considera que a } \\
\text { veces no es necesario que se les } \\
\text { pregunten porque sus papás ya conocen } \\
\text { sus gustos } \\
\text { "...me dicen "vamos a ir a comprar, de repente } \\
\text { quieres comer algo", algún dulce o algo; pero en } \\
\text { realidad creo que ya saben mis gustos". Joven } 3\end{array}$ & $\begin{array}{l}\text { Cuando se les } \\
\text { pregunta a los } \\
\text { jóvenes si desean } \\
\text { algo en especial, } \\
\text { generalmente } \\
\text { piensan } \\
\text { chocolates } \\
\text { golosinas. } \\
\text { “.. y ahí digo } \\
\text { canchita, chocolate; } \\
\text { pero no es que }\end{array}$ \\
\hline
\end{tabular}




\begin{tabular}{|c|c|c|c|}
\hline & & $\begin{array}{l}\text { "creo que más o menos ya saben lo que me gusta } \\
\text { pero antes de comprar me dicen “¿quieres algo } \\
\text { en especial?”. Joven } 4\end{array}$ & $\begin{array}{l}\text { siempre } r \text { esté } \\
\text { involucrado en las } \\
\text { compras". Joven } 4 \\
\text { Algunos jóvenes } \\
\text { mencionaron que } \\
\text { cuando se les } \\
\text { preguntaba qué } \\
\text { querían de especial, } \\
\text { no se les ocurría } \\
\text { nada, pero era más } \\
\text { fácil si iban al } \\
\text { supermercado y lo } \\
\text { veían. (importancia } \\
\text { de visibilidad en el } \\
\text { punto de compra) } \\
\text { "Cuando mi mamá } \\
\text { me pregunta } \\
\text { "quieres que } \\
\text { compre algo? Estoy } \\
\text { yendo" no se me } \\
\text { ocurre nada, pero si } \\
\text { voy y lo veo sín. } \\
\text { Joven 9 } \\
\text { 3 jóvenes resaltan la } \\
\text { importancia de su } \\
\text { opinión en las } \\
\text { compras debido a } \\
\text { que les gusta } \\
\text { cocinar. }\end{array}$ \\
\hline \multirow[t]{2}{*}{$\begin{array}{l}2 . \\
\text { Percepci } \\
\text { ón de la } \\
\text { marca } \\
\text { San } \\
\text { Fernand } \\
\text { o } \\
\end{array}$} & $\begin{array}{l}2 . \quad 1 \\
\text { ¿Qué es } \\
\text { la marca } \\
\text { San } \\
\text { Fernand } \\
\text { o para } \\
\text { ustedes? }\end{array}$ & $\begin{array}{l}\text { 2.1. Significado de la marca San Fernando } \\
\text { - La mitad de los entrevistados } \\
\text { relacionaron la marca con sus productos } \\
\text { y la otra mitad con el slogan. }\end{array}$ & $\begin{array}{l}\text { No hay nuevas } \\
\text { categorías }\end{array}$ \\
\hline & $\begin{array}{l}2 . \quad 2 \\
\text { ¿Cómo } \\
\text { lo } \\
\text { describi } \\
\text { rían si } \\
\text { fuera }\end{array}$ & $\begin{array}{l}\text { 2. } 2 \text { Descripción de marca equivalente a una } \\
\text { imagen } \\
\text { - El } 40 \% \text { de los jóvenes entrevistados } \\
\text { relacionaron la imagen con el logo de } \\
\text { SF. }\end{array}$ & $\begin{array}{l}\text { Solo dos de los } \\
\text { jóvenes } \\
\text { relacionaron la } \\
\text { marca con algo } \\
\text { familiar }\end{array}$ \\
\hline
\end{tabular}




\begin{tabular}{|c|c|c|c|}
\hline & $\begin{array}{l}\text { una } \\
\text { imagen? }\end{array}$ & $\begin{array}{l}\text { "El logo, el pollo o el ave dibujado con el fondo } \\
\text { azul, blanco". Joven } 2 \\
\text { "El logo azul y un calendario que había a mi casa } \\
\text { hace años con chanchitos, pollitos, pavitos". } \\
\text { Joven } 4\end{array}$ & $\begin{array}{l}\text { "Yo me imagino } \\
\text { una reunión } \\
\text { familiar, lo que te } \\
\text { transmite la marca } \\
\text { es como algo muy } \\
\text { familia, creo que no } \\
\text { tiene nada que ver, } \\
\text { pero eso siento". } \\
\text { Joven } 8\end{array}$ \\
\hline & $\begin{array}{l}2.3 \text { \&Y si } \\
\text { fuera } \\
\text { una } \\
\text { persona } \\
?\end{array}$ & $\begin{array}{l}\text { 2.3 Descripción de marca equivalente a una } \\
\text { persona. } \\
\text { - El } 80 \% \text { de los entrevistados se } \\
\text { personifica a la marca San Fernando } \\
\text { como un hombre, de contextura gruesa, } \\
\text { de personalidad amable y bonachona. } \\
\text { "Gordito, alto, chef, buena gente". Joven } 10 \\
\text { "Gordito, con bigote y su gorrito de chef". Joven } \\
2 \\
\text { "Gordito, estatura mediana, cachetón, rosado } \\
\text { con su gorrito de chef, pero en una parrilla. } \\
\text { Carismático, alegre, el que une a la familia". } \\
\text { Joven } 2\end{array}$ & $\begin{array}{l}\text { El 50\% de los } \\
\text { jóvenes personifica } \\
\text { a la marca usando } \\
\text { un mandil blanco, } \\
\text { que lo relacionan } \\
\text { con la limpieza y la } \\
\text { buena imagen de la } \\
\text { marca. } \\
\text { "Yo me imagino un } \\
\text { carnicero, gordito, } \\
\text { tamaño peruano, } \\
\text { pero bonachón, con } \\
\text { nariz de chanchito, } \\
\text { rosadito, todo } \\
\text { vestido de blanco, } \\
\text { impecable". Joven } \\
5 \\
\text { "Hombre, gordito, } \\
\text { estatura mediana, } \\
\text { mandil blanco, } \\
\text { impecable". Joven } \\
2\end{array}$ \\
\hline & $\begin{array}{l}2.4 \\
\text { ¿Saben } \\
\text { cuántos } \\
\text { años } \\
\text { tiene la } \\
\text { empresa } \\
\text { ? }\end{array}$ & $\begin{array}{l}\text { 2. } 4 \text { Percepción de antigüedad de la marca } \\
\text { - Con excepción de una joven, todos los } \\
\text { entrevistados consideran que la marca } \\
\text { tiene entre } 120 \text { y } 150 \text { años. }\end{array}$ & $\begin{array}{l}\text { No hay nuevas } \\
\text { categorías }\end{array}$ \\
\hline $\begin{array}{l}3 . \\
\text { Recordac }\end{array}$ & $\begin{array}{l}3.1 \\
\text { ¿Recuer } \\
\text { dan }\end{array}$ & 3.1 Recordación de la comunicación de la marca & $\begin{array}{l}\text { No hay nuevas } \\
\text { categorías }\end{array}$ \\
\hline
\end{tabular}




\begin{tabular}{|c|c|c|c|}
\hline $\begin{array}{l}\text { ión de } \\
\text { campaña }\end{array}$ & $\begin{array}{l}\text { alguna } \\
\text { campañ } \\
\text { a/comun } \\
\text { icación } \\
\text { de la } \\
\text { marca? }\end{array}$ & $\begin{array}{l}\text { - La primera campaña que recuerdan los } \\
\text { jóvenes es Jueves de Pavita, seguido por } \\
\text { La Buena Familia. }\end{array}$ & \\
\hline & $\begin{array}{l}3.2 \text { ¿Qué } \\
\text { recuerd } \\
\text { an la } \\
\text { campañ } \\
\text { a de los } \\
\text { apellidos } \\
?\end{array}$ & $\begin{array}{l}\text { 3.2. Recordación de campaña } \\
\text { - Lo que más recordaban los jóvenes de la } \\
\text { campaña eran las vallas publicitarias y } \\
\text { los camiones, seguido por las redes } \\
\text { sociales. } \\
\text { "Las vallas publicitarias y que de la nada veías } \\
\text { al costado un camión de SF con cualquier } \\
\text { apellido, en lugar de el nombre San Fernando". } \\
\text { Joven } 9 \\
\text { "Camiones y vallas con los apellidos". Joven } 5 \\
\text { "Igual, facebook, camiones y vallas". Joven } 1\end{array}$ & $\begin{array}{l}\text { No hay nuevas } \\
\text { categorías }\end{array}$ \\
\hline & $\begin{array}{l}+ \\
\text { ¿Recuer } \\
\text { dan qué } \\
\text { quería } \\
\text { comunic } \\
\text { ar? }\end{array}$ & $\begin{array}{l}\text { - El 100\% de los jóvenes percibió la } \\
\text { campaña como una búsqueda de } \\
\text { inclusión de las familias a la familia San } \\
\text { Fernando. } \\
\text { "Querían hacer sentir a todos parte de san } \\
\text { Fernando". Joven } 6 \\
\text { "Que tu familia también era la buena familia". } \\
\text { Joven } 7 \\
\text { "Tu perteneces a SF y SF es parte de tu familia". } \\
\text { Joven } 9\end{array}$ & $\begin{array}{l}\text { No hay nuevas } \\
\text { categorías }\end{array}$ \\
\hline & $\begin{array}{l}3.3 \text { ¿Qué } \\
\text { les gustó } \\
\text { o } \\
\text { disgustó } \\
\text { ? ¿Por } \\
\text { qué? }\end{array}$ & $\begin{array}{l}\text { 3.3 Percepción de la campaña } \\
\text { - En términos generales la campaña sí } \\
\text { agradó a los jóvenes, pero sintieron que } \\
\text { las redes sociales les llegaron a saturar. } \\
\text { "Sí me gustó bastante porque creo que fue } \\
\text { impactante, fue el inicio de que SF empezó a } \\
\text { hacer buena publicidad". Joven } 4 \\
\text { "Súper inclusiva, veías todo tipo de apellidos y } \\
\text { que fue bien impactante porque la veías en todas } \\
\text { partes". Joven } 5 \\
\text { "A mí me pareció súper original porque a quién } \\
\text { no le jala el ojo ver el apellido de tu familia ahí, } \\
\text { sonríes". Joven } 4 \\
\text { "A mi también me gustó la publicidad pero en } \\
\text { un momento ya aburrió ... y te llevaba a decir }\end{array}$ & $\begin{array}{lr}\text { Los jóvenes } \\
\text { justifican } \\
\text { molestia ru } \\
\text { saturación con el } \\
\text { uso descontinuado } \\
\text { de facebook de las } \\
\text { amas de casa o } \\
\text { personas mayores } \\
\text { que no utilizan } \\
\text { redes sociales con } \\
\text { la misma } \\
\text { frecuencia. } \\
\text { "Yo creo que duró } \\
\text { tanto porque no } \\
\text { todo el mundo tiene }\end{array}$ \\
\hline
\end{tabular}




\begin{tabular}{|c|c|c|c|}
\hline & & $\begin{array}{l}\text { "ya estoy cansado de esta vaina de los apellidos" } \\
\text { todo tiene su tiempo". Joven } 7\end{array}$ & $\begin{array}{l}\text { la misma } \\
\text { continuidad de } \\
\text { entrar a Facebook, } \\
\text { hay gente que entra } \\
\text { todos los días y hay } \\
\text { gente que entra una } \\
\text { vez a la semana". } \\
\text { Joven } 6 \\
\text { "Y la gente que vio } \\
\text { el domingo le puso } \\
\text { "share" recién". } \\
\text { Joven 9 }\end{array}$ \\
\hline & $\begin{array}{l}\text { PASAR } \\
\text { SPOT }\end{array}$ & $\begin{array}{l}\text { Todas miran el spot con atención pero serios, } \\
\text { solo sonríen cuando mencionan que la abuelita } \\
\text { los obliga a repetir. }\end{array}$ & \\
\hline $\begin{array}{l}4 . \\
\text { Percepci } \\
\text { ón de las } \\
\text { tácticas } \\
\text { de } \\
\text { storytelli } \\
\text { ng. }\end{array}$ & $\begin{array}{l}\text { 4.1 ¿Qué } \\
\text { piensan } \\
\text { de los } \\
\text { spots? }\end{array}$ & $\begin{array}{l}\text { 4.1 Opinión de los spots } \\
\text { • La mayoría de los jóvenes resalta la } \\
\text { identificación con al menos un tipo de } \\
\text { familia } \\
\text { "Las costumbres, los que comen con los codos } \\
\text { en la mesa. No hay forma que no te sientas } \\
\text { identificado". Joven } 6 \\
\text { "Por lo menos con alguna te vas a identificar". } \\
\text { Joven } 8 \\
\text { - El 50\% de los jóvenes entrevistados } \\
\text { también resaltan la diversidad de las } \\
\text { familias del comercial } \\
\text { "Es inclusión". Joven } 5 \\
\text { "Es el Perú". Joven } 2 \\
\text { “...mucha diversidad, inclusión; y eso es el } \\
\text { Perú". Joven } 4\end{array}$ & $\begin{array}{l}\text { No hay nuevas } \\
\text { categorías }\end{array}$ \\
\hline & $\begin{array}{l}4.2 \quad \text { ¿Si } \\
\text { San } \\
\text { Fernand } \\
\text { o nos } \\
\text { contara } \\
\text { una } \\
\text { historia, } \\
\text { cuál } \\
\text { sería? }\end{array}$ & $\begin{array}{l}\text { 4. 2Historia percibida, contada por San } \\
\text { Fernando. } \\
\text { - Todos los jóvenes relacionaron la } \\
\text { historia que cuenta SF con la unión } \\
\text { familiar y su importancia. } \\
\text { "Lo importante de compartir y reunirse en la } \\
\text { mesa". Joven } 1 \\
\text { "La reunión familia en una casa". Joven } 10 \\
\text { "Lo importante que es la familia sin importar el } \\
\text { tipo de familia que sea". Joven } 8\end{array}$ & $\begin{array}{l}\text { No hay nuevas } \\
\text { categorías }\end{array}$ \\
\hline
\end{tabular}




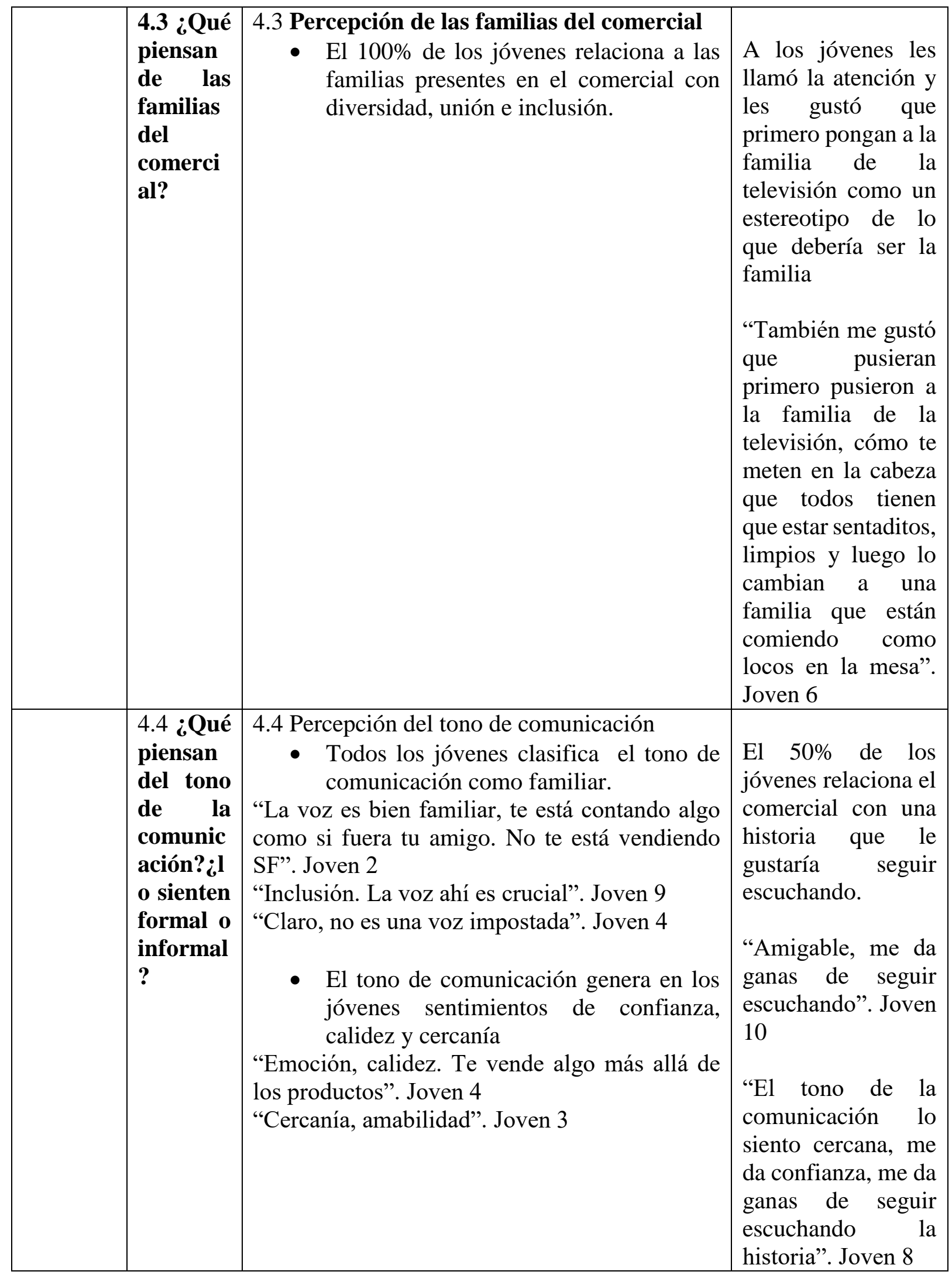




\begin{tabular}{|c|c|c|c|}
\hline $\begin{array}{l}5 . \\
\text { Percepci } \\
\text { ón de } \\
\text { marca } \\
\text { antes de } \\
\text { la } \\
\text { campañ } \\
\text { a }\end{array}$ & $\begin{array}{l}5.1 \\
\text { ¿Recuer } \\
\text { dan } \\
\text { haber } \\
\text { compra } \\
\text { do San } \\
\text { Fernand } \\
\text { o antes } \\
\text { de esta } \\
\text { campañ } \\
\text { a? }\end{array}$ & $\begin{array}{l}\text { 5.1 Preferencia por San Fernando antes de la } \\
\text { campaña de Los Apellidos. } \\
\text { - Todos recuerdan comprar San Fernando } \\
\text { antes de la campaña } \\
\text { - Antes de la campaña, la mayoría de los } \\
\text { jóvenes entrevistados, relacionaban San } \\
\text { Fernando solo con la navidad } \\
\text { "Exacto, antes era como que SF igual a navidad, } \\
\text { ahora es SF todos los días". Joven } 6 \\
\text { "Mi mente estaba más ligada a la navidad". } \\
\text { Joven } 8 \\
\text { - El } 40 \% \text { recuerda San Fernando porque lo } \\
\text { relaciona con el ticket que le daban a sus } \\
\text { padres para el pavo en navidad }\end{array}$ & $\begin{array}{l}\text { No hay nuevas } \\
\text { categorías }\end{array}$ \\
\hline \multirow[t]{2}{*}{$\begin{array}{l}6 . \\
\text { Fidelidad } \\
\text { de marca }\end{array}$} & $\begin{array}{l}6.1 \text { ¿Por } \\
\text { qué se } \\
\text { consider } \\
\text { an } \\
\text { consumi } \\
\text { dores de } \\
\text { SF? }\end{array}$ & $\begin{array}{l}\text { 6.1 Motivación de compra de la marca } \\
\text { - El } 60 \% \text { de los jóvenes entrevistados } \\
\text { justificó su preferencia por SF por su } \\
\text { calidad } \\
\text { "Yo por la calidad, la calidad de San Fernando } \\
\text { es inigualable. Si ha habido días que llegué tarde } \\
\text { al mercado y me han dado el último pollo X... } \\
\text { pero cuando compras algo San Fernando sabes } \\
\text { que nunca va a estar viejo, nunca va a estar duro, } \\
\text { siempre va a estar fresco". Joven } 9 \\
\text { "Yo compro porque viene embasado y te dura } \\
\text { un montón; y por la calidad, el sabor y el precio } \\
\text { que me parece que sí justifica". Joven } 6 \\
\text { - El } 30 \% \text { sostuvo que lo consumía porque } \\
\text { lo encontraba en su casa }\end{array}$ & $\begin{array}{l}\text { Los jóvenes } \\
\text { entrevistados que } \\
\text { no realizan las } \\
\text { compras en su casa, } \\
\text { manifestaron } \\
\text { conocer más acerca } \\
\text { de los productos } \\
\text { embasados } \\
\text { enlatados que del } \\
\text { pollo que se compra } \\
\text { en su casa } \\
\text { “Al momento de } \\
\text { comer pollo, nunca } \\
\text { pregunto qué pollo } \\
\text { es, solo como. Pero } \\
\text { sí, a veces he } \\
\text { abierto la refri y } \\
\text { visto productos". } \\
\text { Joven } 4\end{array}$ \\
\hline & $\begin{array}{l}6.2 \text { ¿Qué } \\
\text { cosa solo } \\
\text { tiene SF } \\
\text { que la } \\
\text { compete } \\
\text { ncia no? }\end{array}$ & $\begin{array}{l}\text { - El } 40 \% \text { de los jóvenes resaltó la } \\
\text { comunicación de San Fernando con sus } \\
\text { consumidores como algo propio solo de } \\
\text { SF } \\
\text { "Tipo de comunicación e inclusión, busca llegar } \\
\text { a todos, hasta a una pareja de lesbianas, quiere }\end{array}$ & $\begin{array}{l}\text { No hay nuevas } \\
\text { categorías }\end{array}$ \\
\hline
\end{tabular}




\begin{tabular}{|l|l|l|l|}
\hline & $\begin{array}{l}\text { llegar a todos, sin importar su orientación } \\
\text { sexual". Joven 8 }\end{array}$ & \\
\hline
\end{tabular}

\section{DISCUSIÓN}

Las tácticas de storytelling utilizadas por la marca San Fernando en su campaña de relanzamiento de "Los Apellidos" fueron recursos claves para lograr conectar emocionalmente con el público y transcender más allá de sus productos. El concepto de La Buena Familia estaba vinculado con la marca, pero para los consumidores la mejor familia es la propia; por lo que San Fernando decidió revertir el slogan y otorgárselo al público. En consecuencia ahora el concepto que se plantea de La Buena Familia involucra a todas las familias peruanas.

Para lograr una conexión emocional San Fernando decidió relatar una historia utilizando la estrategia del storytelling. Entre los objetivos de la campaña estaba generar identificación y conexión emocional con el consumidor, siendo auténticos, y rompiendo el estereotipo de la familia nuclear (mamá, papá y dos hijos) para presentar un modelo de familia expandida (tíos, sobrinos, abuelos, etc.). Asimismo, se tenía como objetivo dar el primer paso a la construcción de una lovemark, incluyendo en el posicionamiento de la marca atributos emocionales y aumentar la intensión de compra.

Entonces, las tácticas concretas de storytelling que se emplearon en esta exitosa campaña fueron la utilización de familias reales en el comercial, la grabación de las familias en su propia casa, la flexibilidad en los guiones, así como el dejar la cámara grabando sola por largos minutos, la utilización de un lenguaje informal o cercano, y el convocar a familias de diversos niveles socioeconómicos con diferentes costumbres. 
Luego de realizar los 4 focus group con 16 amas de casa entre 45 y 55 años, y 19 jóvenes entre 20 y 25 años del nivel socioeconómico $\mathrm{AB}$, se concluye en términos generales que la marca San Fernando es percibida positivamente por todos los entrevistados, y que las tácticas de storytelling han sido en su mayoría efectivamente recepcionadas por el target, aunque de distinto modo en el caso de las amas de casa y los jóvenes.

\section{Rol y percepción en la compra}

Las amas de casa aparecen como decisor de la compra en un $100 \%$ y para la mayoría de ellas la marca San Fernando significa pavos, pollos y garantía, desde hace muchos años. Sin embargo, el posicionamiento que perciben de la marca tiene relación con la unión familiar y las cenas navideñas, y la personifican como un hombre joven, "bonachón" y alegre, que le gusta mucho la cocina.

En contraposición los jóvenes solo son influenciadores de compra ya que pocas veces la efectúan. Ellos relacionan la marca San Fernando directamente con la presentación de sus productos, seguido por la calidad y el eslogan. Tienen más presente sus embutidos o productos enlatados ya que sostienen que no pueden asegurar si el pollo que comen es de la marca San Fernando debido a que lo consumen directamente en el plato.

De igual manera, refiriéndonos a la imagen que tienen los jóvenes de San Fernando, está en su mayoría relacionada con los productos que vende y no a la unión familiar, ellos personifican la marca como un hombre de contextura gruesa, de personalidad amable y bonachona. Varios de ellos le agregaron un gorro de chef y traje blanco a la personificación como símbolo de limpieza y pulcritud. Casi todos perciben la marca como mucho más antigua de lo que es. "Yo le pongo por lo menos 85". (Joven 8)

\section{Recordación de la campaña}


En cuanto a recordación de marca, la mitad de las amas de casa entrevistadas tiene a la campaña de "Los Apellidos" como top of mind en las más recordadas, y lo que mejor evocan es la rima de los apellidos con los hábitos alimenticios de la familia. Ellas la recuerdan con agrado y resaltan la unión familiar.

En este mismo aspecto para los jóvenes, el comercial más mencionado fue Jueves de Pavita y lo que más impacto les causó de la campaña de Los Apellidos son las vallas publicitarias y camiones, seguido por las redes sociales. Resaltan la interacción generada por la marca hace unos años, ya que consideran que involucró notoriamente a los consumidores, especialmente a personas mayores que ellos. La campaña agradó bastante a todos los jóvenes entrevistados, aunque la mayoría de ellos sintió que la comunicación en redes sociales los saturó.

\section{Percepción de tácticas de storytelling}

Centrándonos específicamente en las tácticas de storytelling percibidas, todos los entrevistados, incluyendo jóvenes y amas de casa, coincidieron en que el comercial apelaba directamente a lo emotivo, debido a las mencionadas tácticas. Además, se considera que la historia contada mantiene relación directa con la unión familiar. "El producto que te da SF

es la décima parte de todo lo que te puede ofrecer la marca, que da unión familiar,... algo más que solamente la comida que te vas a comer”. (Joven 7)

Refiriéndonos específicamente a la táctica de aparición de familias de distintos niveles socioeconómicos, tanto amas de casa como jóvenes, consideraban que este recurso transmitía pluralidad y diversidad. Sienten que San Fernando es una marca que se dirige a toda clase de público y es integradora, ya que perciben que tiene a todos en cuenta. No es en vano que hayan dicho: "creo que marca mucho la diversidad del Perú, diferentes sociedades, diferentes apellidos". (Joven 9) Los jóvenes se sintieron más identificados con las costumbres espontáneas que vieron en el comercial. 
En cuanto al tono de comunicación, tanto amas de casa como jóvenes, lo experimentan más natural que informal, y advierten que la marca establece una comunicación fresca y cercana con sus consumidores. Es por ello que mencionan: “...tono informal, un tono familiar, con mucho calor, te contagia, te inmiscuye dentro de algún grupo". (Ama de casa 3)

Además, los entrevistados resaltan la naturalidad en el comportamiento de las familias ya que no relacionan sus actitudes con lo comúnmente visto en un comercial, sino como una historia que les gustaría seguir escuchando. De ahí lo mencionado: “el tono de la comunicación lo siento cercano, me da confianza, me da ganas de seguir escuchando la historia". (Joven 8). "Siento que han ido a la casa de una de las familias, han puesto la cámara y han fluido.”. (Joven 6)

\section{Percepción de marca previa a la campaña}

En cuanto a la percepción de marca previa de la campaña, todos los entrevistados recuerdan haber comprado San Fernando antes de la campaña de relanzamiento, pero consideran que no la tomaban mucho en cuenta y que su frecuencia de compra ha aumentado. Para las amas de casa era una marca vinculada únicamente al pavo, y para los jóvenes solamente a la navidad y al ticket del pavo que se les otorgaba a sus padres en fechas especiales.

Cabe resaltar que las amas de casa manifestaron dificultad para recordar la marca antes de la campaña, ya que no tenían ninguna comunicación en mente. En cambio, los jóvenes sostuvieron sí acordarse de la marca desde siempre, debido a que sus padres compraban los productos de San Fernando.

Fidelización de la marca, a partir de las tácticas de storytelling 
Las amas de casa están fidelizadas por la marca San Fernando ya que la consideran la de mayor calidad, que asegura garantía y tiene buena distribución. A pesar de que las amas de casa tengan un concepto muy positivo de la intangibilidad de la marca San Fernando como la transmisión de unión familiar e igualdad, consideran que la razón por la que compran la marca se relaciona a su calidad y practicidad de sus productos.

La mayoría de jóvenes manifestaron no ser compradores recurrentes ya que encuentran los productos en su hogar, pero sí consideran que tienen una buena relación con la marca: la ven como una persona respetable pero amigable. Es decir, hay altísimas probabilidades de que cuando ellos se conviertan en decisores de compra para su hogar, decidan adquirir San Fernando.

\section{Conclusión}

Por lo tanto, se concluye que:

- $\quad$ El grado en el que las amas de casa valoran la unión familiar que transmite San Fernando es más notorio que en los jóvenes, quienes relacionan a la marca más con sus productos.

- La imagen renovada y juvenil de San Fernando ha penetrado de mejor manera en las amas de casa ya que perciben una personalidad de marca más fresca, aunque sin perder la tradición que identifica a la marca. Para los jóvenes San Fernando continúa siendo una persona un poco mayor que ellos, pero con la que se podría bromear, cuidando ciertos límites.

- A pesar de que las amas de casa no tenían un recuerdo claro de las campañas de San Fernando por separado, sí ha quedado en ellas el concepto de cohesión de familias auténticas, que la marca buscó transmitir desde su relanzamiento

- Indudablemente, las tácticas de storytelling utilizadas en la campaña de "Los Apellidos" han otorgado a la marca una imagen integradora de las familias peruanas y ha generado identificación de parte de todos los consumidores. Sin embargo, tanto jóvenes como amas de casa sostienen que la motivación principal para la elección del 
producto continúa siendo los beneficios racionales como calidad, distribución y garantía.

- A pesar de que han pasado ya cinco años desde el relanzamiento de San Fernando, la campaña cuenta con un gran índice de recordación entre los consumidores entrevistados, ya que la mayoría rememora la campaña con bastante facilidad y asocia el concepto de unión familiar a la marca.

- $\quad$ Todos los objetivos planteados por San Fernando según las necesidades de la empresa en ese entonces (generar identificación con el consumidor, lograr incluir en el posicionamiento de la marca atributos emocionales relacionados a valores familiares y aumentar la intención de compra) se han cumplido, apoyados en gran medida por el correcto uso de las tácticas del estudiado storytelling. San Fernando ahora es parte de las familias peruanas y ha conseguido entrar a sus hogares volviéndolos parte de su historia de unión familiar.

\section{Referencias}

Alimentici, I. (18 de julio de 2012). Productos Avícolas San Fernando. Lima, Lima, Lima.

Bernard, S. C. (2010). Documentary Storytelling. Estados Unidos: Elsevier.

Brakus, J. (2009). Brand Experience: What is it? How is it Measured? Does it affect Loyalty? Estados Unidos: -.

Chiui, A. (4 de junio de 2012). www.gestión.pe. Recuperado el 22 de setiembre de 2014, de www.gestion.pe: http://blogs.gestion.pe/anunciasluegoexistes/2012/06/san-fernando-y-susjueves-de-pavita.html

Collantes, X. R. (2010). Marcas para vender, historias para vivir. Marca, narración y sentido. Barcelona: Universidad Pompeu Fabra.

Conto, J. G. (2011). Manual de Semiótica. Lima: Universidad de Lima. 
Educativa, G. (11 de abril de 2013). youtube.com. Recuperado el 10 de octubre de 2014, de youtube.com: https://www.youtube.com/watch?v=SD_dJA7KmWk

Gaitan, V. (20 de mayo de 2011). http://cocacolabyvalentinagaitan.com. Recuperado el 22 de octubre de 2014, de http://cocacolabyvalentinagaitan.com/: http://cocacolabyvalentinagaitan.blogspot.com/

Iglesias, D. (20 de agosto de 2012). soyunamarca.com. Recuperado el 22 de octubre de 2014, de soyunamarca.com: http://www.soyunamarca.com/2012/08/la-historia-de-lego-y-el-poderdel-storytelling/

Jenkins, H. (2008). Convergence Culture. -: Paidos Ibérica.

Klingenberger, J. P. (18 de noviembre de 2013). Lovemarks y San Fernando. Lima, Lima, Lima.

Lopez-Hermida-Russo, A., \& Vargas-Monardes, J. (2013). La politica relatada: el Storytelling de Barack Obama en el marco de la Operación Gerónimo. Palabra Clave, 12-44.

Lundqvist, A., Liljander, V., Gummerus, J., \& Riel, A. v. (2013). The impact of storytelling on the consumer brand experience: The case of a firm-originated story. -: Henry Stewart Publications.

Martínez, L. V. (2013). Digital storytelling: una nueva estrategia para narrar historias y adquirir competencias por parte de los futuros maestros. Asturias.

Melgosa, J. I. (1998). Cómo elaborar un proyecto. En J. I. Ruiz Olabuénaga, I. Aristegui, \& L. Melgosa, Cómo elaborar un proyecto. Bilbao: Universidad de Deusto.

Mora, P., \& Livat, F. (2013). Does storytelling add value to fine Bordeaux wines? Science Direct, 3-10.

Nadiefirma. (2011). slideshare.net. Recuperado el 21 de setiembre de 2014, de slideshare.net: http://es.slideshare.net/sadith34/trabajo-final-san-fernando

Nuñez, V. (26 de 02 de 2014). vilmanunez.com. Recuperado el 20 de 10 de 2014, de vilmanunez.com: Storytelling es el arte de contar una historia usando lenguaje sensorial presentado de tal forma que trasmite a los oyentes la capacidad de interiorizar, comprender y crear significado personal de ello.

Pacheco, A. (18 de julio de 2013). www.scribd.com. Recuperado el 20 de setiembre de 2014, de www.scribd.com: http://es.scribd.com/doc/119742890/Analisis-Economico-de-la-avicolaperuana-San-Fernando

Pattern, R. (2011). Getting Started in Transmedia Storytelling. California: Robert Patten Corporation.

Richard, E. (2011). Storytelling, Narrativas de Campaña. Campañas electorales para la presidencia en Colombia, 2010. Opera, 129-145. 
Saavedra, M. (7 de agosto de 2014). www.elcomercio.pe. Recuperado el 18 de setiembre de 2014, de www.elcomercio.pe: http://elcomercio.pe/economia/negocios/san-fernando-competiramercado-alimentos-congelados-noticia-1748030

Sadowsky, J., \& Roche, L. (2013). Las siete reglas del storytelling. Buenos Aires: Gramica.

Salomón, C. (2012). Storytelling. La máquina de gabricar historias y formatear mentes. Barcelona: Peninsula.

U.Pacífico. (2012). Las mejores prácticas de marketing. Lima: Universidad del Pacífico.

Villanueva, D. (24 de julio de 2013). www.mercadeando.com. Recuperado el 15 de setiembre de 2014, de www.mercadeando.com: http://mercadeando.com/blog/la-transcategorizacioncompetitiva-conservas-de-pollo-san-fernando/

Wikipedia. (13 de octubre de 2013). wikipedia.com. Recuperado el 22 de noviembre de 2014, de wikipedia.com: http://es.wikipedia.org/wiki/Narraci\%C3\%B3n_transmedia 